\title{
A Synergic Activity of Urea/Butyl Imidazolium Ionic Liquid Supported on UiO-66-NH2 Metal-Organic Framework for Synthesis of Oximes
}

\author{
Askari, Saeed; Jafarzadeh, Mohammad; Christensen, David Benjamin; Kegnæs, Søren
}

Published in:

Catalysis Letters

Link to article, DOI:

$10.1007 / \mathrm{s} 10562-020-03203-1$

Publication date:

2020

Document Version

Peer reviewed version

Link back to DTU Orbit

Citation (APA):

Askari, S., Jafarzadeh, M., Christensen, D. B., \& Kegnæs, S. (2020). A Synergic Activity of Urea/Butyl Imidazolium Ionic Liquid Supported on UiO-66-NH2 Metal-Organic Framework for Synthesis of Oximes. Catalysis Letters, 150, 3159-3173. https://doi.org/10.1007/s10562-020-03203-1

\section{General rights}

Copyright and moral rights for the publications made accessible in the public portal are retained by the authors and/or other copyright owners and it is a condition of accessing publications that users recognise and abide by the legal requirements associated with these rights.

- Users may download and print one copy of any publication from the public portal for the purpose of private study or research.

- You may not further distribute the material or use it for any profit-making activity or commercial gain

- You may freely distribute the URL identifying the publication in the public portal 


\section{算 Springer}

\section{A synergic activity of urea/butyl imidazolium ionic liquid supported on UiO-66-NH2 metal-organic framework for synthesis of oximes}

\begin{tabular}{|r|l|}
\hline Journal: & Catalysis Letters \\
\hline Manuscript ID & CATLET-2020-0142.R2 \\
\hline Manuscript Type: & Original Manuscript \\
\hline Complete List of Authors: & $\begin{array}{l}\text { Askari, Saeed; Razi University } \\
\text { Jafarzadeh, Mohammad; Razi University, Faculty of Chemistry } \\
\text { Christensen, David Benjamin; Technical University of Denmark, } \\
\text { Chemistry } \\
\text { Kegnæs, Søren; Technical University of Demark, Department of } \\
\text { Chemistry; }\end{array}$ \\
\hline Keywords: & $\begin{array}{l}\text { Supported Ionic-liquid Phase, Metal-organic frameworks, UiO-66-NH2, } \\
\text { Oxime synthesis }\end{array}$ \\
\hline &
\end{tabular}

\section{SCHOLARONE \\ Manuscripts}




\title{
A synergic activity of urea/butyl imidazolium ionic liquid supported on UiO-66- $\mathrm{NH}_{2}$ metal- organic framework for synthesis of oximes
}

Saeed Askari, ${ }^{1}$ Mohammad Jafarzadeh, ${ }^{1 *}$ David Benjamin Christensen, ${ }^{2}$ Søren Kegnæs ${ }^{2}$

${ }^{1}$ Faculty of Chemistry, Razi University, Kermanshah 67144-14971, Iran

${ }^{2}$ Department of Chemistry, Technical University of Denmark, 2800 Kgs. Lyngby, Denmark

*Corresponding author (M. Jafarzadeh): Email: m.jafar@razi.ac.ir

\begin{abstract}
An efficient supported ionic liquid catalyst is designed for condensation reaction of aldehydes and ketones. The Zr-based metal-organic framework (MOF), UiO-66- $\mathrm{NH}_{2}$, was initially functionalized with $N, N^{\prime}$-dibutyl imidazolium ionic liquid ( $\mathrm{UiO}-66-\mathrm{NH}_{2}-\mathrm{ILBr}^{-}$), and then urea was attached to the ionic liquid (IL) to form a task-specific IL. Bromide was exchanged with tetrafluoroborate and the catalyst exhibits excellent performance for the synthesis of oximes. The ionic liquid/urea coupling showed a synergistic effect on the efficiency of the reaction. The supported catalyst system was recycled simply by filtration and reused for five times without significant decrease in its activity. The catalyst was characterized with PXRD, FTIR, TGA, XPS, BET, FE-SEM, EDS, elemental mapping and elemental analysis (CHN).
\end{abstract}

Keyword: Supported Ionic-liquid Phase; Metal-organic frameworks; UiO-66- $\mathrm{NH}_{2}$; Oxime synthesis.

\section{Introduction}

Supported ionic liquids (SILs) and supported ionic liquid phase (SILPs) have attracted some interests due to their unique properties and activities compared to conventional ionic liquids (ILs) [1,2]. A SILP material is defined as a thin and multilayer film (a few nanometer thick) of the ionic liquid physisorbed on the surface of porous materials [3], while in SILs a monolayer of an ionic liquid is covalently immobilized on the surface (sometimes called as supported ionic liquid-like phase; SILLP) [1]. These concepts diminish the typical issue of the ILs such as high cost, large volume usage, high viscosity (cause difficulty in mass transfer and reactant diffusion) [4], and the need for liquid-liquid extraction for their recovery. Heterogenization of ILs on support materials (e.g. silica, alumina, 
titania, activated carbon, polymer) [5-7] not only reduce the amount of ionic liquid, provide short diffusion distance (due to a nanometer thickness) [4], makes for easier handling, recycling and longterm stability of ionic liquids [6], and reduce potential risk to the environment due their poor biodegradability [1], but also promotes the performance of the hybrid materials in their applications [6].

Although, SILPs have some advantages such as easy preparation and simple operation particularly in fixed-bed reactors for gas phase reactions, but they suffer from pore blocking and instability in the reaction medium especially in liquid phase. The IL can be removed from the surface (leaching) by force of mechanical stirring and/or dissolving in reaction media $[1,8,9]$. In contrast, by covalent grafting of ILs to the functional groups on the surface of the support, the stability and durability of SILs in organic syntheses may improve significantly. SILs have been used as hosts for organocatalysts [10], metal-complexes [8], and metal nanoparticles [6,11] and generated task-specific ionic liquids (TSILs) [12-15] and specifically the concept of supported ionic liquid catalysts (SILC) [16-19]. Metal-organic frameworks (MOFs), as class of promising porous materials, have been employed as suitable supports for immobilizing ILs [20,21] and catalysts [22,23] due to their high surface area, large pore volume, and available/accessible pores [24]. A synergic effect arising from their hybridization have previously been shown to enhance the efficiency of the catalytic reactions [20,21]. MOF/TSIL hybrid materials have been used for various organic reactions such as acetalization of benzaldehydes with glycol [25], selective oxidation of cyclohexenes [26] and benzyl alcohols [27,28], adsorptive desulfurization [29,30], Knoevenagel condensation [31], cycloaddition of $\mathrm{CO}_{2}$ with epoxides [32-34] and synthesis of biodiesels [35].

Oximes are important intermediates for synthesis of nitriles [36], amides (Beckmann rearrangement) [37-39], nitrones, hydroximinoyl chlorides, and chiral $\alpha$-sulfinyl oximes [40]. They are also used for preparation of carbonyl compounds [41] and metal complexes [42], protecting carbonyl compounds, inhibiting enzymes [43] and manufacturing of pharmaceutical products and insecticides [44]. Although various methods have been developed recently for the synthesis of oximes such as decomposition of tosylhydrazones [45], oxidation of methylarenes (in the presence of a nitrogen source) [46], oxidation of primary amines [47], ammoximation of different ketones and aldehydes using polyexometalates [48,49], and transoximation [50], but the conventional method is still considered due to the simplicity of the procedure. Oximes are generally synthesized via a 
condensation reaction of carbonyl compounds (aldehydes and ketones) with hydroxylamine in acidic or basic conditions [51]. Since hydroxylamine is dangerous to handle and use [52], hydroxylamine hydrochloride is generally employed to generate in-situ hydroxylamine in the reaction medium, with only water and $\mathrm{HCl}$ as by-products [51]. Besides conventional conditions for the synthesis of oximes, microwave-assisted [53], ultrasonic [43], and mechanochemical [54] methods have been also developed. ILs have found much interest as an alternative reaction media for the synthesis of oximes [55-57]. It is expected that the application of SILs in the synthesis of oximes can find some benefits in an aspect of economic and environment.

In the present work, zirconium-based MOF, UiO-66- $\mathrm{NH}_{2}$, is modified by a post-synthesis with imidazolium bromide $\left(\mathrm{ILBr}^{-}\right)$for the preparation of supported ionic liquid on the surface of the MOF. The SIL was further functionalized with urea to prepare a TSIL. Urea offers basic sites and hydrogen bond donors [58] for catalyzing organic synthesis of oximes, similar to the glycine-catalyzed synthesis in the previous report [59]. However, the urea-functionalized SIL serves as a catalyst and medium in this work. It is expected that the functionalized MOF exhibits heterogeneous characteristics for the IL and the base.

\section{Experimental}

\subsection{Synthesis of 1,3-bis-(4-bromo-butyl)-3 $\mathrm{H}$-imidazol-1-ium bromide (ILBr-)}

The preparation of the ionic liquid was adopted from a previously reported method [60]. Imidazole (290 mg, $4.3 \mathrm{mmol}$ ) was dissolved in THF (4 mL), and then a solution of sodium hydride (135 $\mathrm{mg}, 5$ $\mathrm{mmol})$ in THF $(3 \mathrm{~mL})$ was slowly added at $0{ }^{\circ} \mathrm{C}$. After $45 \mathrm{~min}$ of stirring at room temperature, 1,4dibromobutane $(0.51 \mathrm{~mL}, 4.3 \mathrm{mmol})$ was added slowly to the above solution and stirred for 2 days. The product was extracted from the reaction mixture using ethyl acetate .In the second step, the product was dissolved in THF and stirred for $45 \mathrm{~min}$. 1,4-dibromobutane (0.55 mL, $4.6 \mathrm{mmol})$ was then added into the mixture and refluxed for 2 days. The final product was isolated by extraction using ethyl acetate. The products were identified by ${ }^{1} \mathrm{H}$ and ${ }^{13} \mathrm{C}$ NMR and the spectra were compared with data for a similar structure [61] (refer to Supporting Information for details).

\subsection{Preparation of UiO-66- $-\mathrm{NH}_{2}-\mathrm{ILBF}_{4}^{-}$-urea}

UiO-66- $\mathrm{NH}_{2}$ was prepared according the method reported in the literature $[62,63]$. The prepared UiO66- $\mathrm{NH}_{2}(0.1 \mathrm{~g})$ was dispersed in $10 \mathrm{~mL}$ DMF in a round-bottomed flask using sonication for $5 \mathrm{~min}$. 
Next, (0.03 mmol, $10 \mathrm{mg}$ ) 1,3-bis-(4-bromo-butyl)-3H-imidazol-1-ium bromide was added to the mixture, and the solution was stirred under reflux for $24 \mathrm{~h}$. Next, $(0.06 \mathrm{mmol}, 3.6 \mathrm{mg})$ urea was added to the mixture to form Task Specific Ionic Liquid (TSIL). After $24 \mathrm{~h}$ stirring under reflux, the precipitate was isolated by centrifugation. The product (UiO-66- $\mathrm{NH}_{2}-\mathrm{ILBr}^{-}$-urea) was washed with DMF, water and ethanol. The supported ionic liquid phase was dried at $80^{\circ} \mathrm{C}$ in an oven for $24 \mathrm{~h}$. In the next step, an anion exchange was carried out by addition of sodium tetrafluoroborate $(0.175 \mathrm{~g}$, $1.5 \mathrm{mmol})$ to the solution of $\mathrm{UiO}-66-\mathrm{NH}_{2}-\mathrm{ILBr}^{-}$-urea $(0.1 \mathrm{~g})$ in acetone $(2 \mathrm{~mL})$ followed by stirred at room temperature for $24 \mathrm{~h}$. The exchanged IL was then filtered and washed with $\mathrm{H}_{2} \mathrm{O}(3 \times 10 \mathrm{~mL})$, EtOH $(3 \mathrm{~mL}), \mathrm{Et}_{2} \mathrm{O}(2.5 \mathrm{~mL})$, and acetone $(2.5 \mathrm{~mL})$. The resulting $\mathrm{UiO}-66-\mathrm{NH}_{2}-\mathrm{ILBF}_{4}^{-}$-urea was dried at $50^{\circ} \mathrm{C}$ in an oven overnight to give the final product.

\subsection{General procedure for the synthesis of oximes}

$0.05 \mathrm{~g}$ of UiO-66- $\mathrm{NH}_{2}-\mathrm{ILBF}_{4}^{-}$-urea dispersed in $1 \mathrm{~mL}$ ethanol was added to a mixture of benzaldehyde $(1 \mathrm{mmol}, 0.11 \mathrm{~mL})$ and hydroxylamine hydrochloride $(1.5 \mathrm{mmol}, 0.1 \mathrm{~g})$. Stirring at 25 ${ }^{\circ} \mathrm{C}$ (room temperature) was continued until the benzaldehyde was consumed, as monitored by thin layer chromatography (TLC). After completion of the reaction, the reaction mixture was added to 10 $\mathrm{mL}$ water and extracted with ether $(3 \times 10 \mathrm{~mL})$. Further purification was accomplished by washing it with ethyl acetate and $n$-hexane. The organic products were identified by ${ }^{1} \mathrm{H}$ and ${ }^{13} \mathrm{C}$ Nuclear Magnetic Resonance (NMR, Bruker $400 \mathrm{MHz}$ ) spectroscopy, by comparing with data in the literature [64]. The catalyst was washed with water and ethanol, and dried at $60{ }^{\circ} \mathrm{C}$ in an oven overnight. The catalyst was reused for several times under the same reaction conditions.

\subsection{Spectral data}

Entry 1 (benzaldehyde oxime): ${ }^{1} \mathrm{H}$ NMR (400 MHz, $d_{6}$-DMSO): $\delta(\mathrm{ppm}) 8.14(\mathrm{~s}, 1 \mathrm{H}), 7.77-7.75$ (d, $2 \mathrm{H}), 7.40-7.38(\mathrm{~m}, 1 \mathrm{H}), 7.03-7.0(\mathrm{dd}, 2 \mathrm{H}) ;{ }^{13} \mathrm{C} \mathrm{NMR}$ (100 MHz, $d_{6}$-DMSO): $\delta$ (ppm) 167.52, 151.64, $131.88,129.71,126.84,118.02,115.06$.

Entry 2 (2-hydroxylbenzaldehyde oxime): ${ }^{1} \mathrm{H}$ NMR (400 MHz, $d_{6}$-DMSO): $\delta$ (ppm) 8.33 (s, 1H), 7.49-7.47 (dd, 1H), 7.25-7.21 (dd, 1H), 6.90-6.86 (m, 2H); ${ }^{13} \mathrm{C}$ NMR (100 MHz, $d_{6}$-DMSO): $\delta(\mathrm{ppm})$ $156.42,147.96,130.93,128.30,119.80,118.72,116.46$.

Entry 3 (2-methylbenzaldehyde oxime): ${ }^{1} \mathrm{H}$ NMR (400 MHz, $d_{6}$-DMSO): $\delta$ (ppm) 8.29 (s, 1H), 7.67$7.64(\mathrm{dd}, 1 \mathrm{H}), 7.50-7.35(\mathrm{td}, 1 \mathrm{H}), 7.08-7.06(\mathrm{~d}, 1 \mathrm{H}), 6.98-6.94(\mathrm{t}, 1 \mathrm{H}), 3.41(\mathrm{~s}, 3 \mathrm{H}) ;{ }^{13} \mathrm{C}$ NMR $(100$ 
MHz, $d_{6}$-DMSO): $\delta$ (ppm) 157.26, 143.86, 131.23, 125.88, 121.38, 121.07, 112.19, 56.10. (Figure S10, Supporting Information)

Entry 4 (3,4,5-trimethoxybenzaldehyde oxime): ${ }^{1} \mathrm{H} \mathrm{NMR}\left(400 \mathrm{MHz}, \mathrm{CDCl}_{3}\right): \delta(\mathrm{ppm}) 8.08(\mathrm{~s}, 1 \mathrm{H})$, $6.84(\mathrm{~s}, 2 \mathrm{H}), 3.90$ (s, 9H); ${ }^{13} \mathrm{C} \mathrm{NMR}\left(100 \mathrm{MHz}, \mathrm{CDCl}_{3}\right): \delta(\mathrm{ppm})$ 153.48, 150.21, 139.71, 127.40, 104.12, 60.95, 56.18. (Figure S11, Supporting Information)

Entry 5 (cinnamaldehyde oxime): ${ }^{1} \mathrm{H}$ NMR (400 MHz, $d_{6}$-DMSO): $\delta(\mathrm{ppm})$ 7.58-7.56 (d, $\left.1 \mathrm{H}\right), 7.42-$ 7.39 (dd, 2H), 7.38-7.36 (t, 1H), 7.33-7.32 (dd, 2H), 7.29 (d, 1H), 6.98-6.95 (d, 1H); ${ }^{13} \mathrm{C}$ NMR (100 MHz, $d_{6}$-DMSO): $\delta$ (ppm) 147.68, 138.35, 136.36, 129.50, 129.36, 127.67, 116.59.

Entry 6 (4-nitrobenzaldehyde oxime): ${ }^{1} \mathrm{H}$ NMR (400 MHz, $d_{6}$-DMSO): $\delta$ (ppm) 8.31 (s, 1H), 8.278.24 (dd, 2H), 7.88-7.84 (dd, 2H); ${ }^{13} \mathrm{C}$ NMR (100 MHz, $d_{6}$-DMSO): $\delta$ (ppm) 147.97, 147.29, 139.96, $127.80,124.45$.

Entry 7 (3-nitrobenzaldehyde oxime): ${ }^{1} \mathrm{H}-\mathrm{NMR}$ (400 MHz, $d_{6}$-DMSO): $\delta(\mathrm{ppm})$ 8.42-8.41 (t, $\left.1 \mathrm{H}\right)$, $8.32(\mathrm{~s}, 1 \mathrm{H}), 8.23-8.20(\mathrm{dd}, 1 \mathrm{H}), 8.06-8.03(\mathrm{dd}, 1 \mathrm{H}), 7.72-7.68(\mathrm{t}, 1 \mathrm{H}) ;{ }^{13} \mathrm{C} \mathrm{NMR}\left(100 \mathrm{MHz}, d_{6^{-}}\right.$ DMSO): $\delta$ (ppm) 148.57, 147.04, 135.39, 132.77, 130.79, 124.11, 121.26.

Entry 8 (2-chlorobenzaldehyde oxime): ${ }^{1} \mathrm{H}$ NMR (400 MHz, $d_{6}$-DMSO): $\delta(\mathrm{ppm}) 8.37$ (s, 1H), 7.83$7.81(\mathrm{dd}, 1 \mathrm{H}), 7.52-7.50(\mathrm{dd}, 1 \mathrm{H}), 7.45-7.42(\mathrm{dd}, 1 \mathrm{H}), 7.40-7.38(\mathrm{dd}, 1 \mathrm{H}) ;{ }^{13} \mathrm{C} \mathrm{NMR}\left(100 \mathrm{MHz}, d_{6^{-}}\right.$ DMSO): $\delta$ (ppm) 144.99, 132.64, 131.40, 130.74, 130.29, 128.01, 127.26.

Entry 9 (4-methoxybenzaldehyde oxime): ${ }^{1} \mathrm{H}$ NMR (400 MHz, $d_{6}$-DMSO): $\delta(\mathrm{ppm}) 8.06(\mathrm{~s}, 1 \mathrm{H})$, 7.96-7.93 (d, 1H), 7.53-7.51 (d, 1H), $7.31(\mathrm{~d}, 1 \mathrm{H}), 6.99-6.95(\mathrm{t}, 1 \mathrm{H}), 3.79(\mathrm{~s}, 3 \mathrm{H}) ;{ }^{13} \mathrm{C}$ NMR $(100$ MHz, $d_{6}$-DMSO): $\delta$ (ppm) 160.25, 148.07, 144.71, 132.76, 128.28, 114.64, 114.13, 55.66. (Figure S12, Supporting Information)

Entry 10 (acetophenone oxime): ${ }^{1} \mathrm{H}$ NMR (400 MHz, $d_{6}$-DMSO): $\delta(\mathrm{ppm}) 7.32-7.27(\mathrm{dd}, 2 \mathrm{H}), 7.21$ 7.19 (dd, 2H), 7.18 (t, 1H), 1.64 (s, 3H); ${ }^{13} \mathrm{C} \mathrm{NMR} \mathrm{(100} \mathrm{MHz,} d_{6}$-DMSO): $\delta$ (ppm) 155.05, 138.11, $128.90,126.60,13.50$.

Entry 11 (cyclohexanone oxime): ${ }^{1} \mathrm{H}$ NMR (400 MHz, $d_{6}$-DMSO): $\delta$ (ppm) 2.40-2.37 (t, 2H), 2.17 $2.14(\mathrm{~m}, 2 \mathrm{H}), 1.58-1.52(\mathrm{~m}, 6 \mathrm{H}) ;{ }^{13} \mathrm{C} \mathrm{NMR}$ (100 MHz, $d_{6}$-DMSO): $\delta$ (ppm) 159.35, 31.80, 27.03, $25.72,24.53$.

\subsection{Characterization techniques}

Powder X-ray diffraction (PXRD) was used to study the crystalline nature of the MOF (UiO-66-NH $\mathrm{NH}_{2}$ before and after modification (fresh and reused catalyst) by a Rigaku D-Max C III diffractometer $(\mathrm{Cu}$ $\mathrm{K} \alpha, \lambda=1.5418 \AA$ ). Infrared spectra were recorded by a Fourier transform infrared spectroscopy (FT- 
IR), from a Bruker vector 22 spectrometer, using $\mathrm{KBr}$ pellets. The chemical composition of the modified MOF was examined by a CHN elemental analyzer (Euro EA - HEKAtech GmbH) under $\mathrm{N}_{2}$ gas flow and X-ray photoelectron spectroscopy (XPS) on a Kratos Axis Ultra-DLS spectrometer (Al $\mathrm{K}_{\alpha}$ source). The data was analyzed using the CasaXPS software. The thermal stability and organic species loading were studied by thermogravimetric analysis (TGA; Perkin Elmer STA 6000) at a heating rate of $10{ }^{\circ} \mathrm{C} \mathrm{min}^{-1}$ under nitrogen flow. The morphology and elemental analysis were carried out by a field emission scanning electron microscope (FE-SEM; FEI NOVA NanoSEM 450) equipped with energy dispersive X-ray spectroscopy (EDX). Platinum spurring was carried out on the samples before analysis to avoid undesirable electron charging. The BET (Brunauer-EmmettTeller) specific surface area and adsorption BJH (Barrett-Joyner-Halenda) pore size/volume of the samples were measured by an automatic porosimeter (Micromeritics, Tristar II 3020). The samples were degassed under vacuum overnight before analysis. TEM images was acquired on a FEI Tecnai T20 G2 instrument at $200 \mathrm{kV}$ from Thermo Fisher Scientific. Powdered samples were placed on holey carbon grids with no prior treatment.

\section{Results and Discussion}

\subsection{Preparation and characterization of $\mathrm{UiO}-66-\mathrm{NH}_{2}-\mathrm{ILBF}_{4}^{-}$-urea catalyst}

After synthesizing the ionic liquid, 1,3-bis-(4-bromo-butyl)-3H-imidazol-1-ium bromide (ILBr-), the UiO-66- $\mathrm{NH}_{2}$ was functionalized by $\mathrm{ILBr}^{-}$and followed by urea. The reaction pathway to prepare $\mathrm{UiO}-66-\mathrm{NH}_{2}-\mathrm{ILBr}^{-}$-urea is given in Scheme 1. In addition, UiO-66- $\mathrm{NH}_{2}-\mathrm{ILBF}_{4}^{-}$-urea was prepared via an anion exchange, $\mathrm{Br}^{-}$replaced by $\mathrm{BF}_{4}^{-}$. The preparation steps were monitored by applying different characterization techniques.

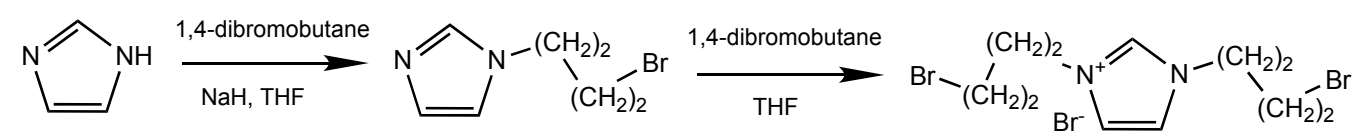



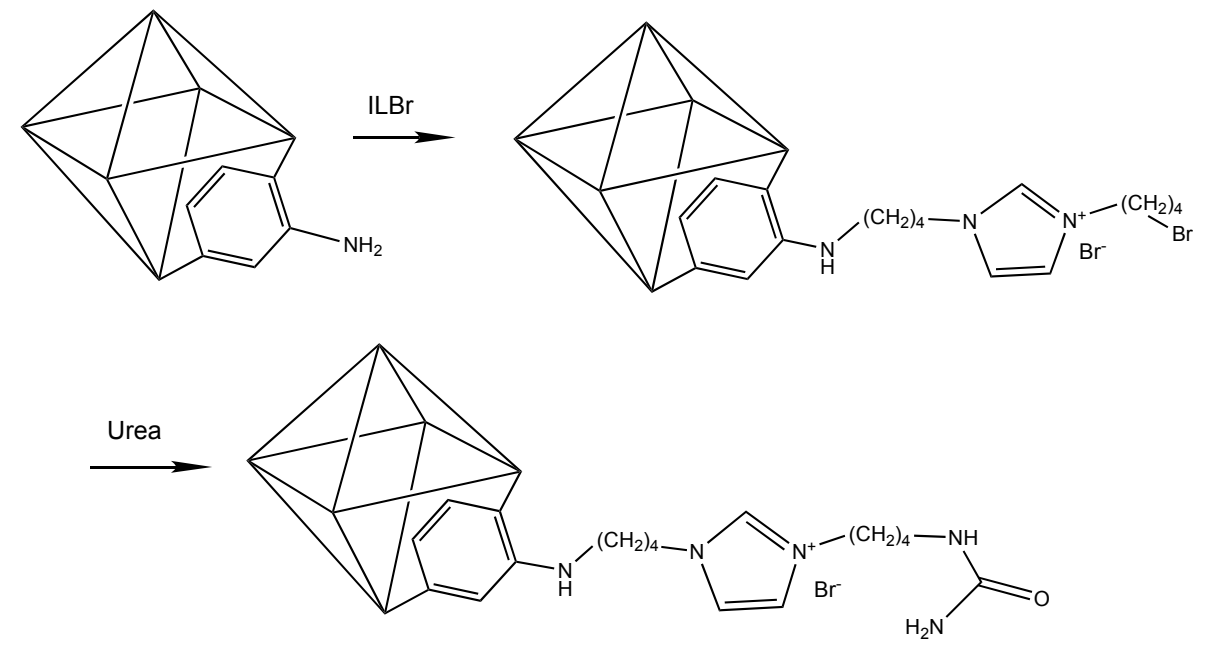

Scheme 1. Preparation of ILBr- and UiO-66-NH${ }^{-}-\mathrm{ILBr}^{-}$-urea.

XRD was used to study the crystalline structure of the UiO-66- $\mathrm{NH}_{2}$ after functionalization by $\mathrm{ILBr}^{-}$ and grafting by urea (Figure 1a). The characteristic diffraction of the UiO-66- $\mathrm{NH}_{2}$ was observed at angles of $14.7^{\circ}, 17.4^{\circ}, 22.2^{\circ}, 25.7^{\circ}, 30.6^{\circ}, 31.1^{\circ}, 35.9^{\circ}, 37.7^{\circ}, 40.1^{\circ}, 43.6^{\circ}, 50.5^{\circ}$, and $56.8^{\circ}$ corresponding to the (222), (400), (511), (600), (711), (731), (820), (751), (664), (933), (955), and (12 42) planes, respectively [65]. The UiO-66- $\mathrm{NH}_{2}-\mathrm{ILBF}_{4}{ }^{-}$-urea showed isostructural and similar pattern to that of the pristine MOF, indicating that the post-synthesis maintained the crystalline structure of the frameworks. Additional diffractions at $17.95^{\circ}, 28.7^{\circ}, 29.25^{\circ}$, and $47.9^{\circ}$ were observed and could be attributed to IL-Urea. 


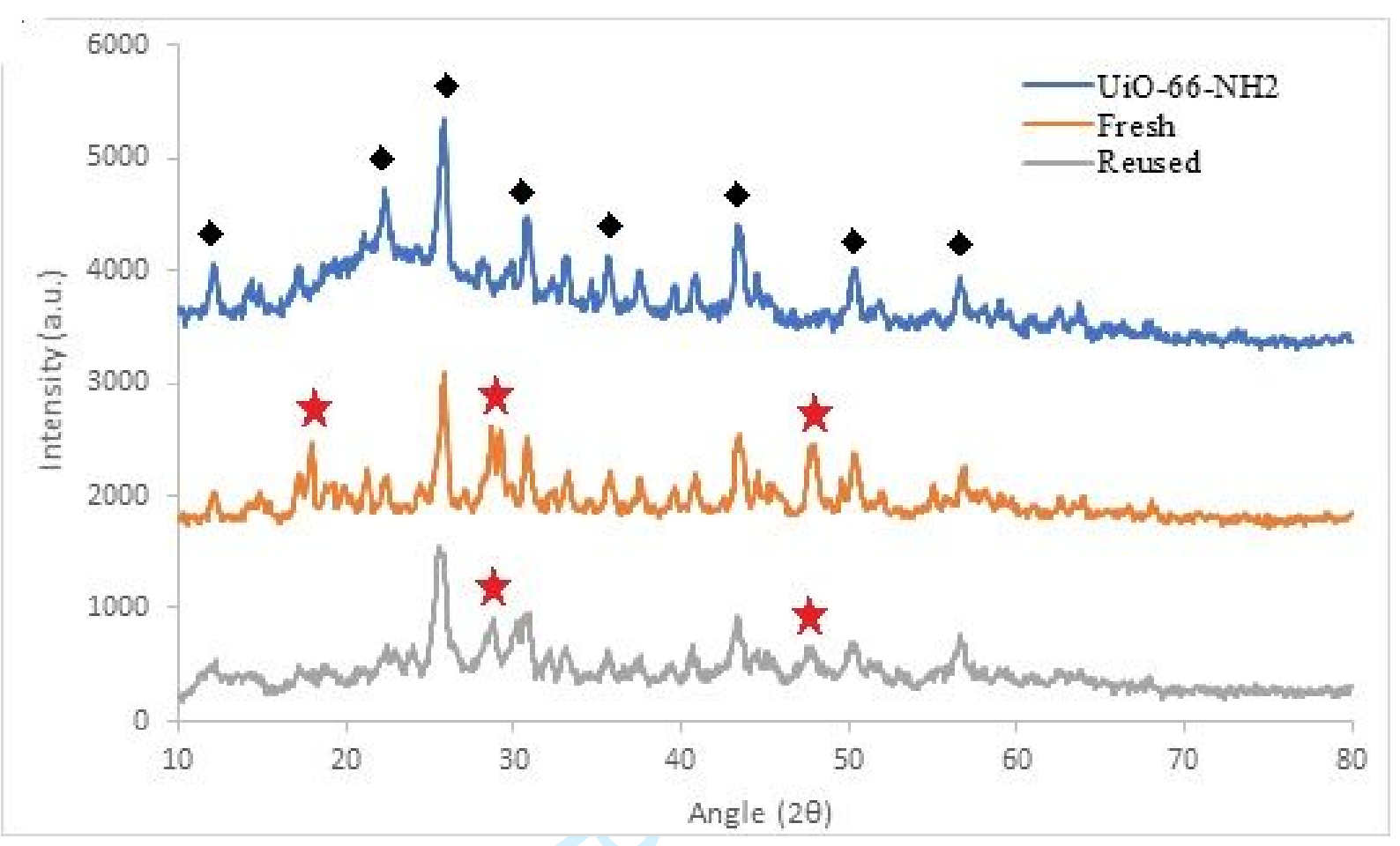

(a)

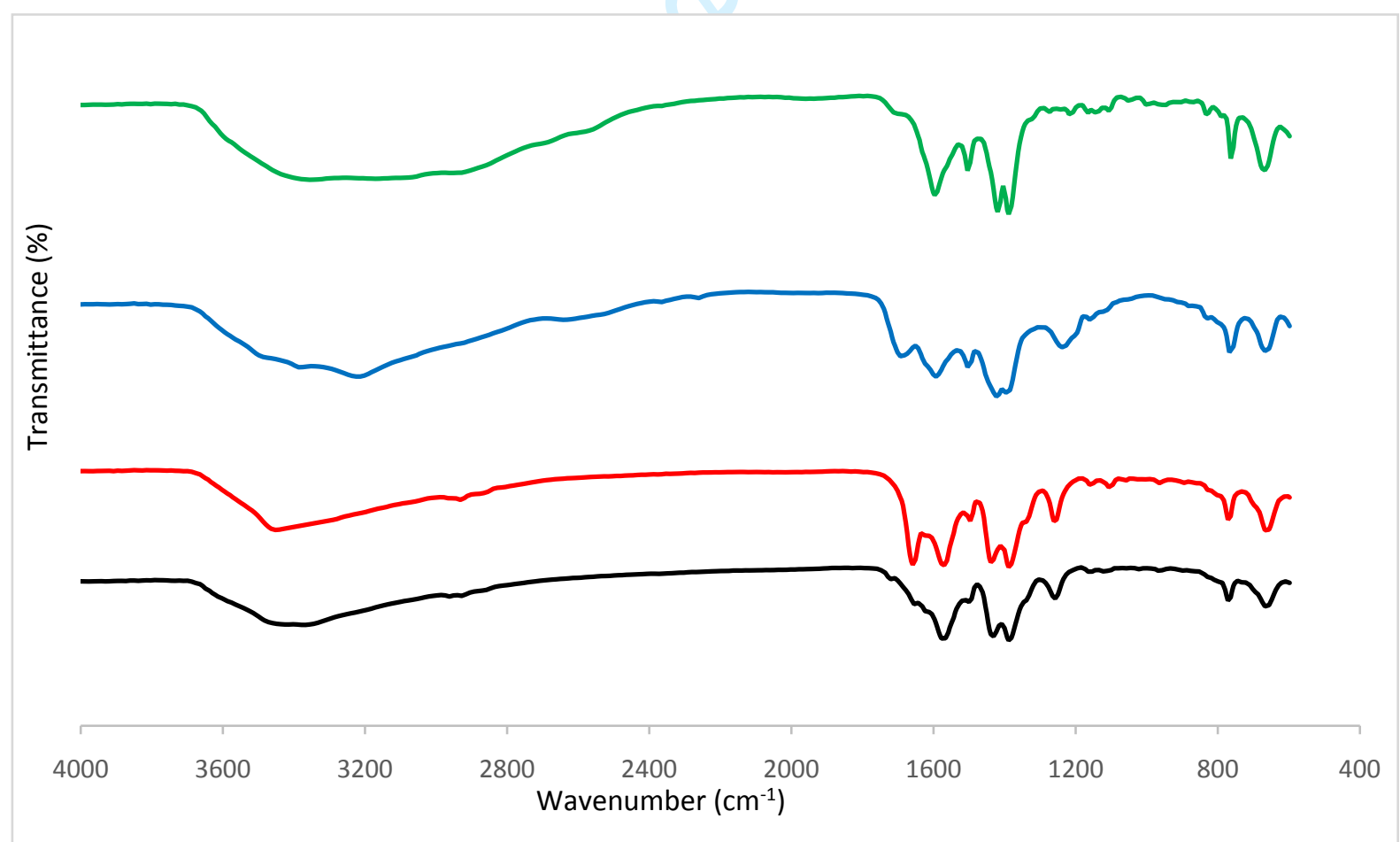

(b) 


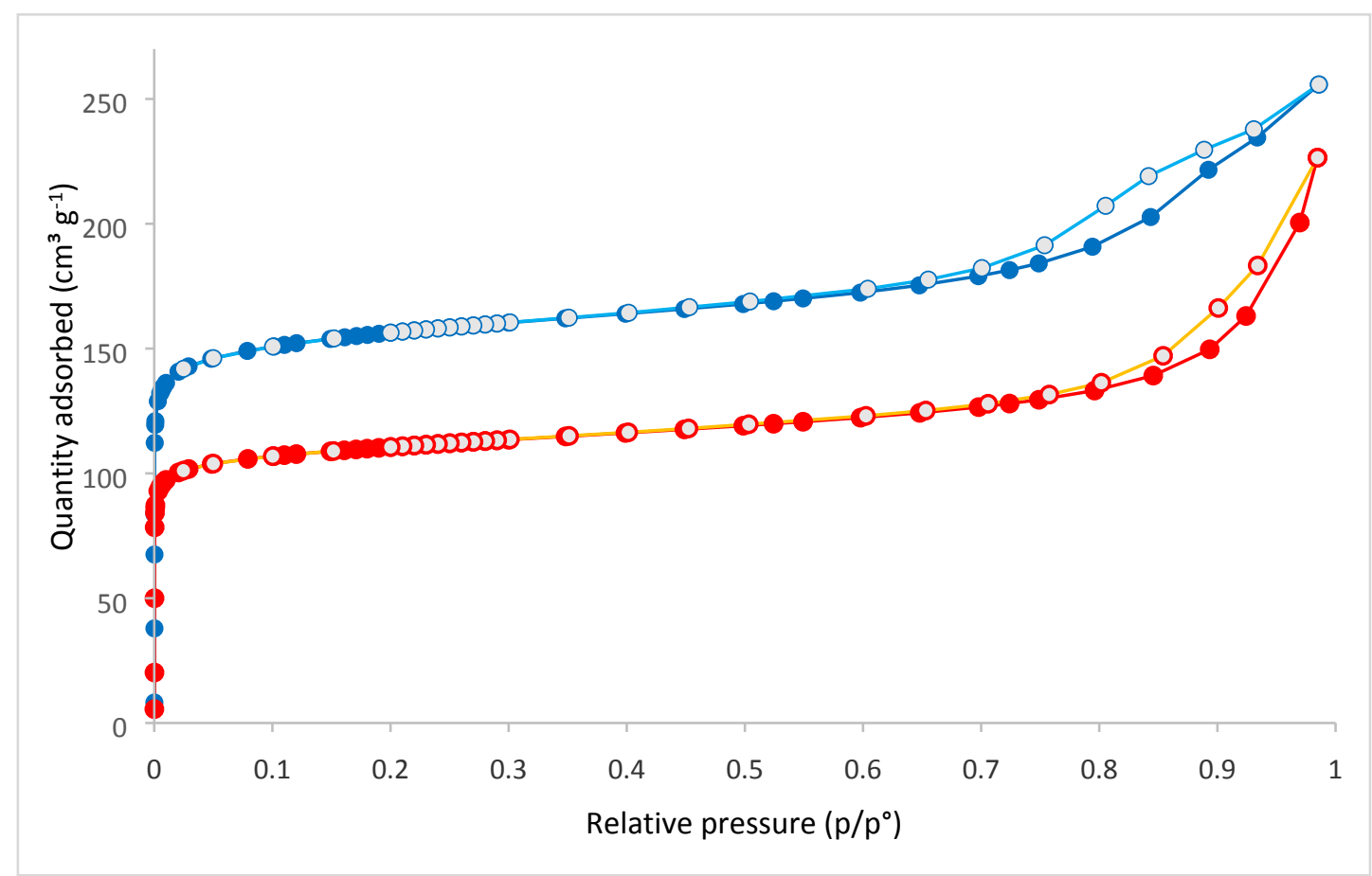

(c)

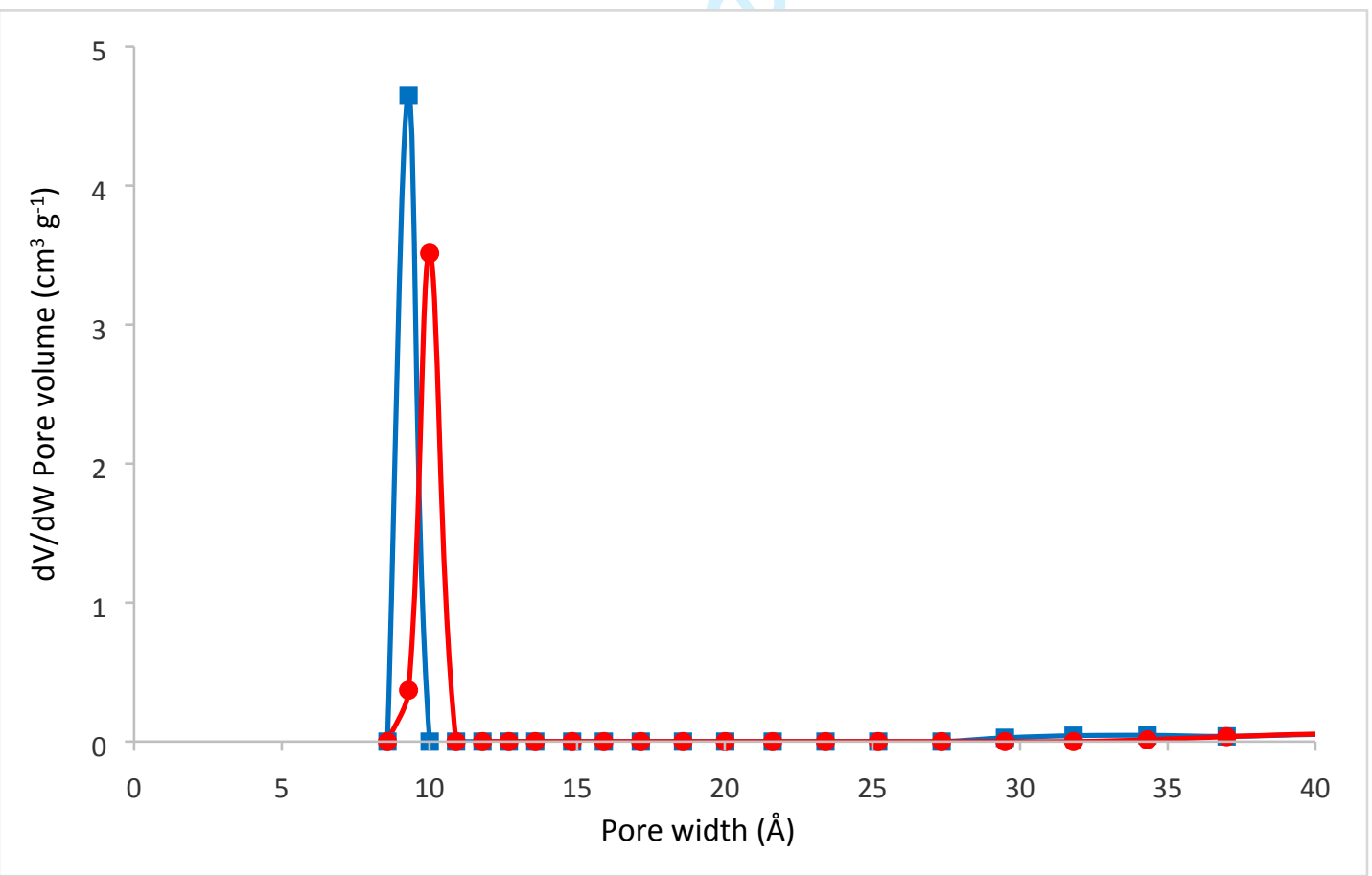

(d)

Figure 1. (a) PXRD patterns of UiO-66- $\mathrm{NH}_{2}-\mathrm{ILBF}_{4}{ }^{-}$-urea in fresh and reused (after five times recycling), and (b) FT-IR spectra of UiO-66- $\mathrm{NH}_{2}$ (black), UiO-66- $\mathrm{NH}_{2}-\mathrm{ILBr}^{-}$(red), fresh UiO-66$\mathrm{NH}_{2}-\mathrm{ILBF}_{4}{ }^{-}$-urea (blue) and reused UiO-66- $\mathrm{NH}_{2}-\mathrm{ILBF}_{4}^{-}$-urea (green). (c) $\mathrm{N}_{2}$ adsorption-desorption 
isotherm and (d) pore size distribution of the fresh (blue) and reused (red), after five times recycling, UiO-66- $\mathrm{NH}_{2}-\mathrm{ILBF}_{4}^{-}$-urea. The solid spheres are referred to adsorption and the gray ones are for desorption.

The functionalization of the MOF was investigated by FT-IR (Figure 1b). The characteristic peaks related to the $\mathrm{N}-\mathrm{H}$ stretch of primary amines $\left(3457 \mathrm{~cm}^{-1}\right.$ and $\left.3351 \mathrm{~cm}^{-1}\right)$, carbonyl stretch $\left(1661 \mathrm{~cm}^{-}\right.$ $\left.{ }^{1}\right), \mathrm{C}-\mathrm{N}$ stretch $\left(1259 \mathrm{~cm}^{-1}\right)$, and $\mathrm{Zr}-\mathrm{O}$ stretch $\left(600-800 \mathrm{~cm}^{-1}\right)$ were observed [65]. A stretching vibration at $503 \mathrm{~cm}^{-1}$ was attributed to $\mathrm{CH}_{2}-\mathrm{Br}$ after attachment of $\mathrm{ILBr}^{-}$to the ligand of the MOF. For UiO-66- $\mathrm{NH}_{2}-\mathrm{ILBF}_{4}^{-}$-urea, the bands at 3370 and $3215 \mathrm{~cm}^{-1}$ were related to the stretching vibration of $\mathrm{N}-\mathrm{H}$ in amines, while the band at $1630 \mathrm{~cm}^{-1}$ is attributed to the amide group in urea. Bands at $1590 \mathrm{~cm}^{-1}$ and $1460 \mathrm{~cm}^{-1}$ were assigned to the $\mathrm{C}=\mathrm{N}$ and imidazolium ring, respectively.

Figure 1c,d demonstrated the $\mathrm{N}_{2}$ adsorption-desorption isotherm and pore size distribution of the MOF. The isotherm showed a type IV hysteresis that is a characteristic pattern for mesoporous materials, while a fast adsorption at low pressure is consistence with microporous materials. Figure 1d showed a uniform distribution of the pore size in the framework. The surface area and porosity of the UiO-66- $\mathrm{NH}_{2}-\mathrm{ILBF}_{4}{ }^{-}$-urea were determined (Table 1). As expected, the surface area and pore size/volume were reduced after modification of UiO-66- $\mathrm{NH}_{2}$. The BET surface area, total pore volume, and average pore size were obtained to be $600 \mathrm{~m}^{2} \mathrm{~g}^{-1}, 0.39 \mathrm{~cm}^{3} \mathrm{~g}^{-1}$, and $0.9 \mathrm{~nm}$, respectively. The pore size of $0.9 \mathrm{~nm}$ belongs to the microporous materials according to the IUPAC classification of porous materials [66].

Table 1. Surface area and porosity of the UiO-66- $\mathrm{NH}_{2}-\mathrm{ILBF}_{4}{ }^{-}-\mathrm{urea}$ in fresh and recycled forms.

\begin{tabular}{|l|l|l|l|}
\hline & UiO-66- $\mathrm{NH}_{2}$ & $\begin{array}{l}\text { UiO-66- }-\mathrm{NH}_{2}-\mathrm{ILBF}_{4}-\text {-urea } \\
\text { (fresh) }\end{array}$ & $\begin{array}{l}\text { UiO-66- } \mathrm{NH}_{2}-\mathrm{ILBF}_{4}-\text {-urea } \\
\text { (recycled) }\end{array}$ \\
\hline BET surface area $\left(\mathrm{m}^{2} \mathrm{~g}^{-1}\right)$ & 1280 & 601 & 427 \\
\hline Total pore volume $\left(\mathrm{cm}^{3} \mathrm{~g}^{-1}\right)$ & 0.60 & 0.39 & 0.34 \\
\hline Average pore size $(\mathrm{nm})$ & 1.89 & 0.93 & 1.0 \\
\hline
\end{tabular}

$\mathrm{CHN}$ analysis was used to determine the amount of organic species loading on the surface of the MOFs (Table 2). The results showed that the content of carbon and nitrogen increased after modification of the UiO-66- $\mathrm{NH}_{2}$ with ionic-liquid. The atomic percentage of carbon and nitrogen decreased after grafting urea to the ionic liquid, which can be related to the presence of heavy 
elements (i.e. Br) in the structure. XPS was also employed for detection the elements and their quantities (Table 2). The presence of relevant elements $(\mathrm{Zr}, \mathrm{O}, \mathrm{C}, \mathrm{N}, \mathrm{Br})$ in the structure of the MOF and the ionic liquid on the surface was verified. There is a difference in the elemental compositions obtained from CHN and XPS techniques due to their different operations applied for the analysis. In $\mathrm{CHN}$, the content of selected elements (e.g. C, N, H) in the entire bulk of the samples is measured, while in XPS, almost all elements (except $\mathrm{H}$ ) in the selected points of the samples in the surface and sub-layer with thickness $<10 \mathrm{~nm}$ is analyzed. Figures S7-S9 (Supporting Information) display the XPS surveys of UiO-66- $\mathrm{NH}_{2}$, UiO-66- $\mathrm{NH}_{2}-\mathrm{ILBr}^{-}$and $\mathrm{UiO}-66-\mathrm{NH}_{2}-\mathrm{ILBr}^{-}$-urea, respectively. For UiO-66- $\mathrm{NH}_{2}$ (Figure $\mathrm{S} 5$ ), the $\mathrm{N} 1 \mathrm{~s}$ peak at $397 \mathrm{eV}$ was attributed to $\mathrm{NH}_{2}$ groups on the organic linkers. For the supported ILs, the $\mathrm{O} 1 \mathrm{~s}$ peaks at 531 and $530.5 \mathrm{eV}$ were assigned to the $\mathrm{C}=\mathrm{O}$ groups in the linker and the urea, respectively (Figure S6 and S7), while the peak at $182 \mathrm{eV}$ corresponded to the $\mathrm{Br}$ $3 \mathrm{p}$ in the C-Br bond (Figure S8). High-resolution XPS and the relevant deconvolution, in Figure 2a, exhibited two components for the $\mathrm{N}$ peak. The peaks at $\sim 401$ and $\sim 399.5 \mathrm{eV}$ were assigned to the cationic $\mathrm{N}$ and the neutral $\mathrm{N}\left(-\mathrm{NH}_{2}\right)$, respectively [67]. The peak at $401 \mathrm{eV}$ confirms the presence of the imidazolium ring in the IL-supported UiO-66- $\mathrm{NH}_{2}$ [68]. High-resolution XPS of the $\mathrm{C} 1 \mathrm{~s}$ peak consists of three fitted peaks at binding energies of 283 and 284 and $290 \mathrm{eV}$ (Figure 2b). The peak at $283 \mathrm{eV}$ was attributed to the C-C aliphatic (alkyl groups of the IL), while the peak at $284 \mathrm{eV}$ was for $\mathrm{C}-\mathrm{N}, \mathrm{C}=\mathrm{C}$, and $\mathrm{C}=\mathrm{N}$ (in the linker and the imidazolium rings) [69]. The peak at $290 \mathrm{eV}$ was also found to be correlated to the $\mathrm{C}=\mathrm{O}$ in the linker and the urea [70].

Table 2. Elemental compositions of the UiO-66- $\mathrm{NH}_{2}$, UiO-66- $\mathrm{NH}_{2}-\mathrm{ILBr}^{-}$and $\mathrm{UiO}-66-\mathrm{NH}_{2}-\mathrm{ILBr}^{-}-$ urea.

\begin{tabular}{|c|c|c|c|c|c|c|c|}
\hline \multirow[t]{2}{*}{ MOFs } & \multicolumn{2}{|c|}{ CHN (At\%) } & \multicolumn{5}{|c|}{ XPS (At\%) } \\
\hline & $\mathbf{C}$ & $\mathbf{N}$ & $\mathbf{Z r}$ & $\mathbf{O}$ & $\mathbf{C}$ & $\mathbf{N}$ & $\mathbf{B r}$ \\
\hline UiO-66-NH ${ }_{2}$ & 21.28 & 4.49 & 2.88 & 31.47 & 60.72 & 4.84 & - \\
\hline UiO-66-NH ${ }_{2}-\mathrm{ILBr}^{-}$ & 24.28 & 5.65 & 2.41 & 23.32 & 64.07 & 2.60 & 7.60 \\
\hline UiO-66-NH $2-\mathrm{ILBr}^{-}$-urea & 18.39 & 3.48 & 7.61 & 30.12 & 37.46 & 0.9 & 23.90 \\
\hline
\end{tabular}




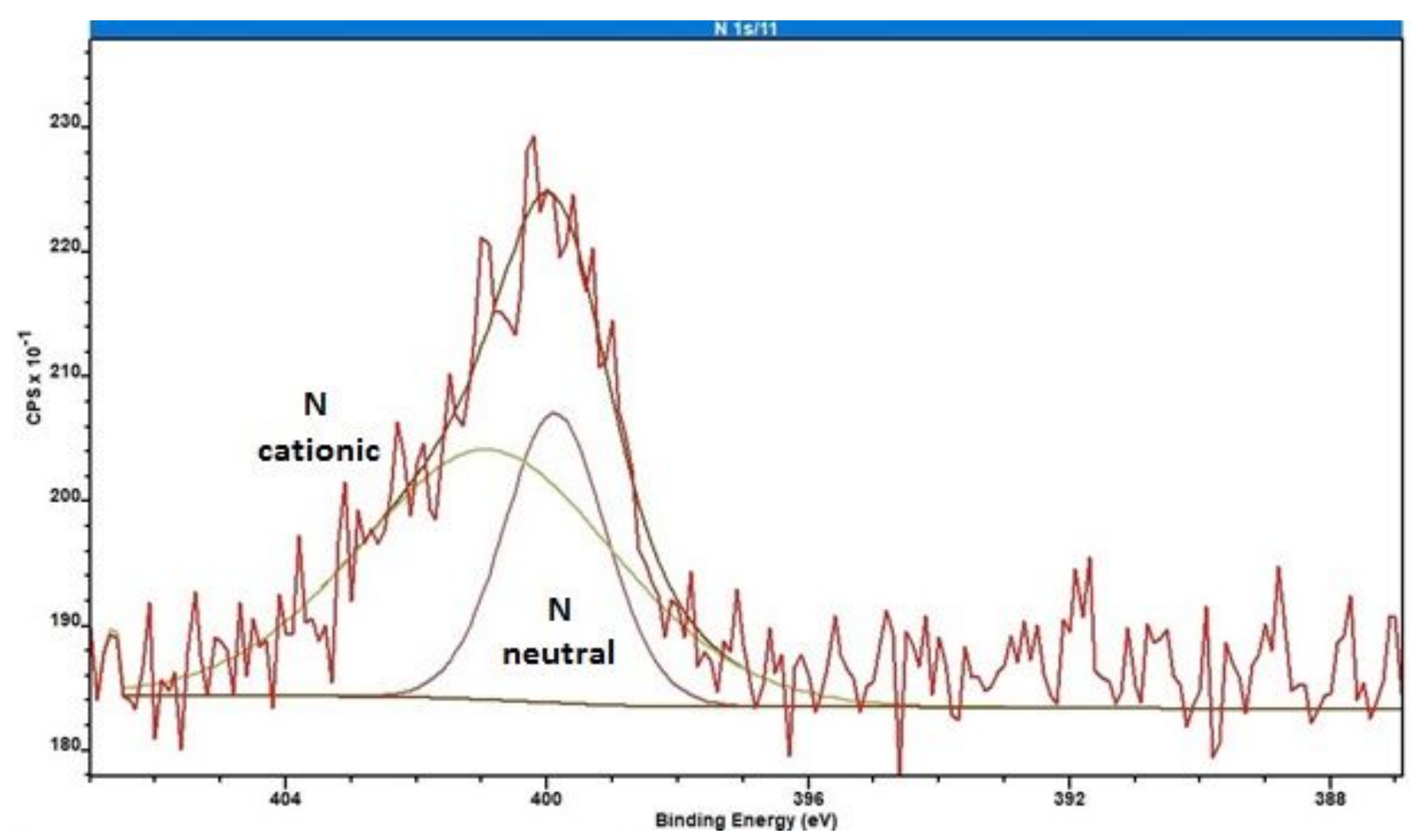

(a)

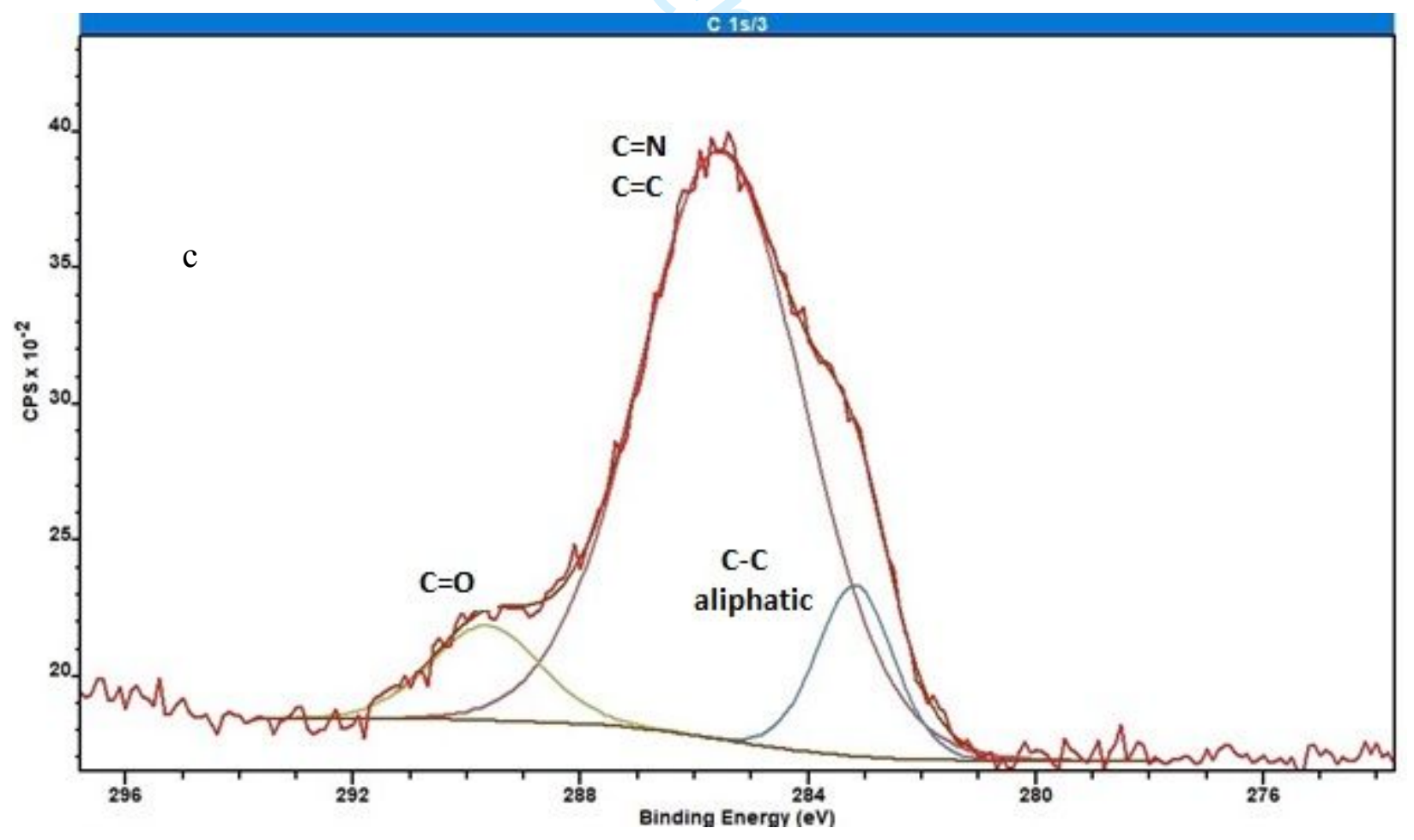

(b)

Figure 2. High resolution XPS of (a) $\mathrm{N}$ 1s for UiO-66- $\mathrm{NH}_{2}-\mathrm{ILBr}^{-}$and (b) $\mathrm{C} 1 \mathrm{~s}$ for UiO-66- $\mathrm{NH}_{2}-$ ILBr-urea. 
The thermal stability and mass loading of ionic-liquid and urea into the framework were studied by TGA. In Figure 3, The UiO-66- $\mathrm{NH}_{2}-\mathrm{ILBF}_{4}{ }^{-}$and $\mathrm{UiO}-66-\mathrm{NH}_{2}-\mathrm{ILBF}_{4}{ }^{-}$-urea showed almost similar thermal stability with the $\mathrm{UiO}-66-\mathrm{NH}_{2}$. An initial weight loss of $\sim 5 \%$ and $\sim 10 \%$ was found for UiO66- $\mathrm{NH}_{2}-\mathrm{ILBF}_{4}{ }^{-}$and UiO-66- $\mathrm{NH}_{2}-\mathrm{ILBF}_{4}{ }^{-}$-urea, respectively at below $\sim 100{ }^{\circ} \mathrm{C}$, while $\sim 20 \%$ weight loss observed for the pristine MOF. The initial weight loss is related to the removal of the residual solvent (e.g. water and/or ethanol) from the pores. Moreover, an additional weight loss was observed at $\sim 180-250{ }^{\circ} \mathrm{C}$ for the modified MOFs, relating to the escape of DMF coordinated to the nodes. Such event was not observed for the UiO-66- $\mathrm{NH}_{2}$ because the MOF activation via a solvent extraction was efficient in removal of DMF. At temperature above $250{ }^{\circ} \mathrm{C}$, slight reduction in the weight might be attributed to the thermal decomposition of the IL [71] and also urea groups in the modified MOFs, and removal of residual coordinated DMF inside the micropore of the UiO-66- $\mathrm{NH}_{2}$ and partial degradation of the MOF structures $\sim 400{ }^{\circ} \mathrm{C}$. A further weight loss at $\sim 500{ }^{\circ} \mathrm{C}$ was observed for the modified and pristine MOFs due to the framework degradation to $\mathrm{ZrO}_{2}$ [65].

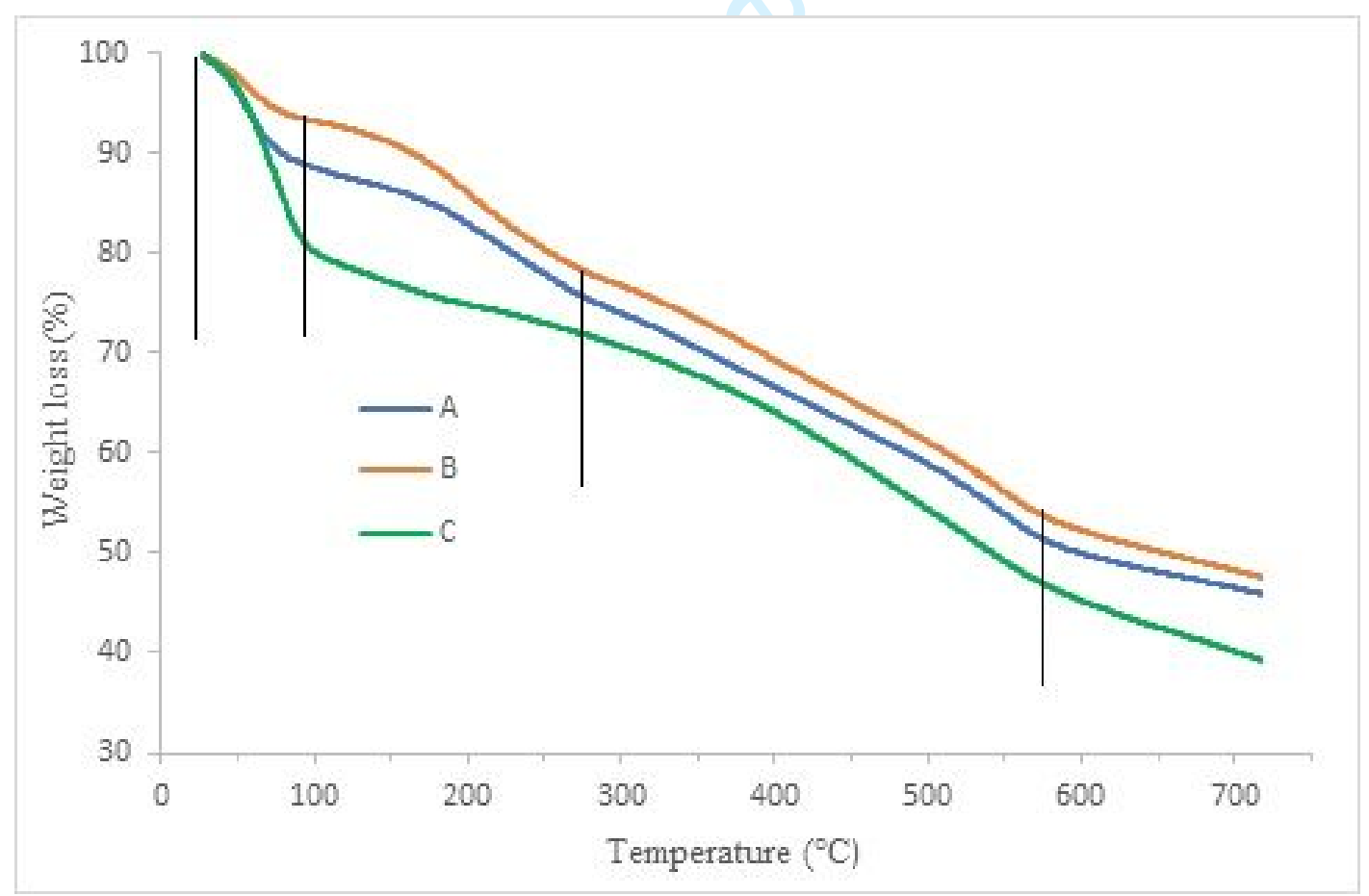

Figure 3. Thermograms of (A) UiO-66- $\mathrm{NH}_{2}-\mathrm{ILBF}_{4}^{-}$, (B) UiO-66- $\mathrm{NH}_{2}-\mathrm{ILBF}_{4}^{-}$-urea, and (C) UiO$66-\mathrm{NH}_{2}$. 
The TEM and SEM images (Figure 4a,b) showed irregular round-shaped particles for UiO-66- $\mathrm{NH}_{2}$ $\mathrm{ILBF}_{4}{ }^{-}$-urea with sizes ranging from 50 to $100 \mathrm{~nm}$. The EDS confirms the existence of the elements incorporated in the MOF (Figure 4c). Zr (5.5\%), O (17.3\%), C (35.6\%), N (7.6\%), B (9.8\%), and F $(24.0 \%)$ were found. The result confirms the presence of $\mathrm{B}$ and $\mathrm{F}$ (corresponding to $\mathrm{BF}_{4}^{-}$) along with other elements in the structure. The trace amount of $\mathrm{Br}$ inferred an almost complete replacement of $\mathrm{Br}^{-}$with $\mathrm{BF}_{4}^{-}$within anion exchange. The elemental mapping demonstrated a homogeneous distribution of elements in the frameworks (Figure 4d).

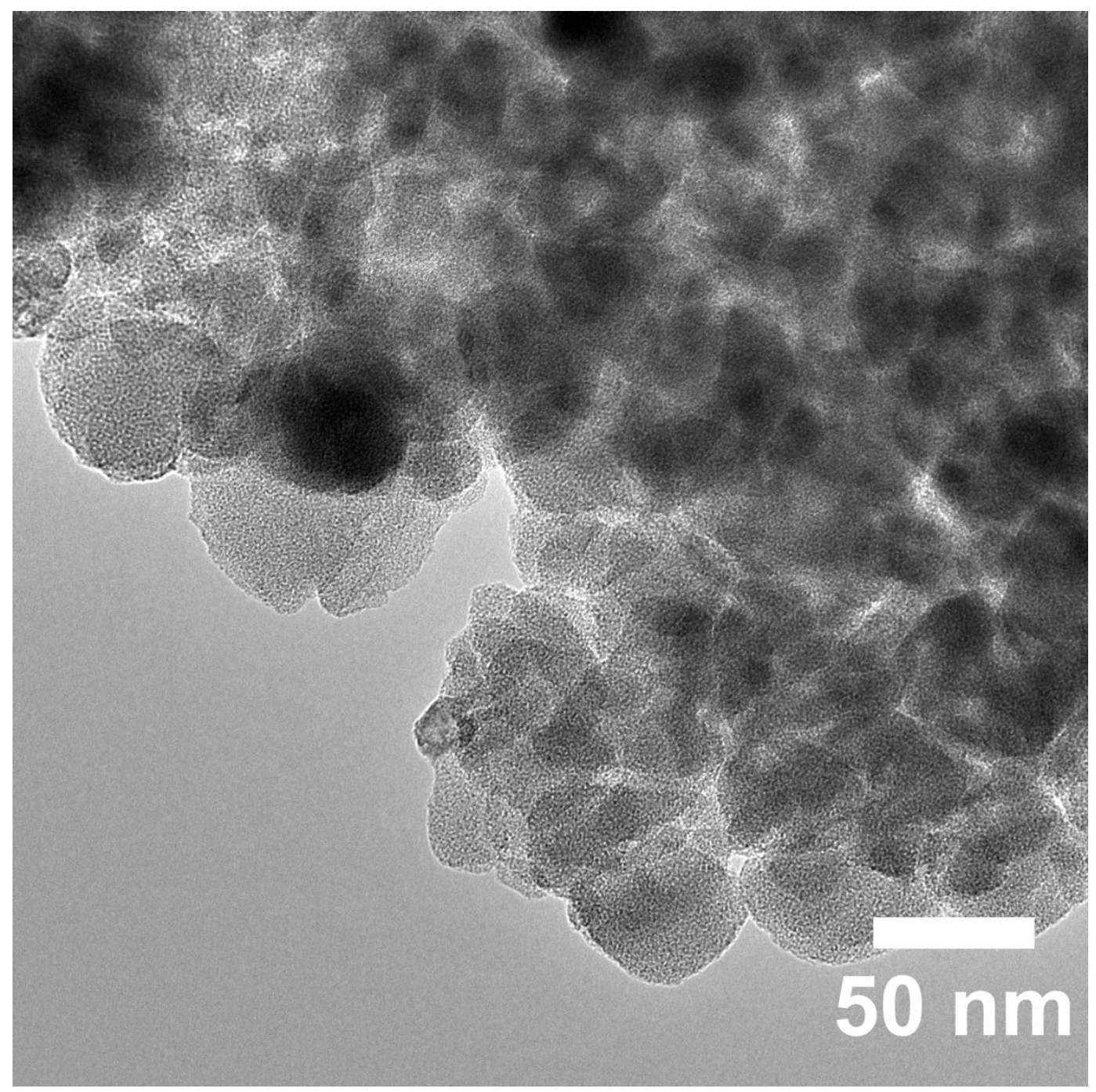

(a) 


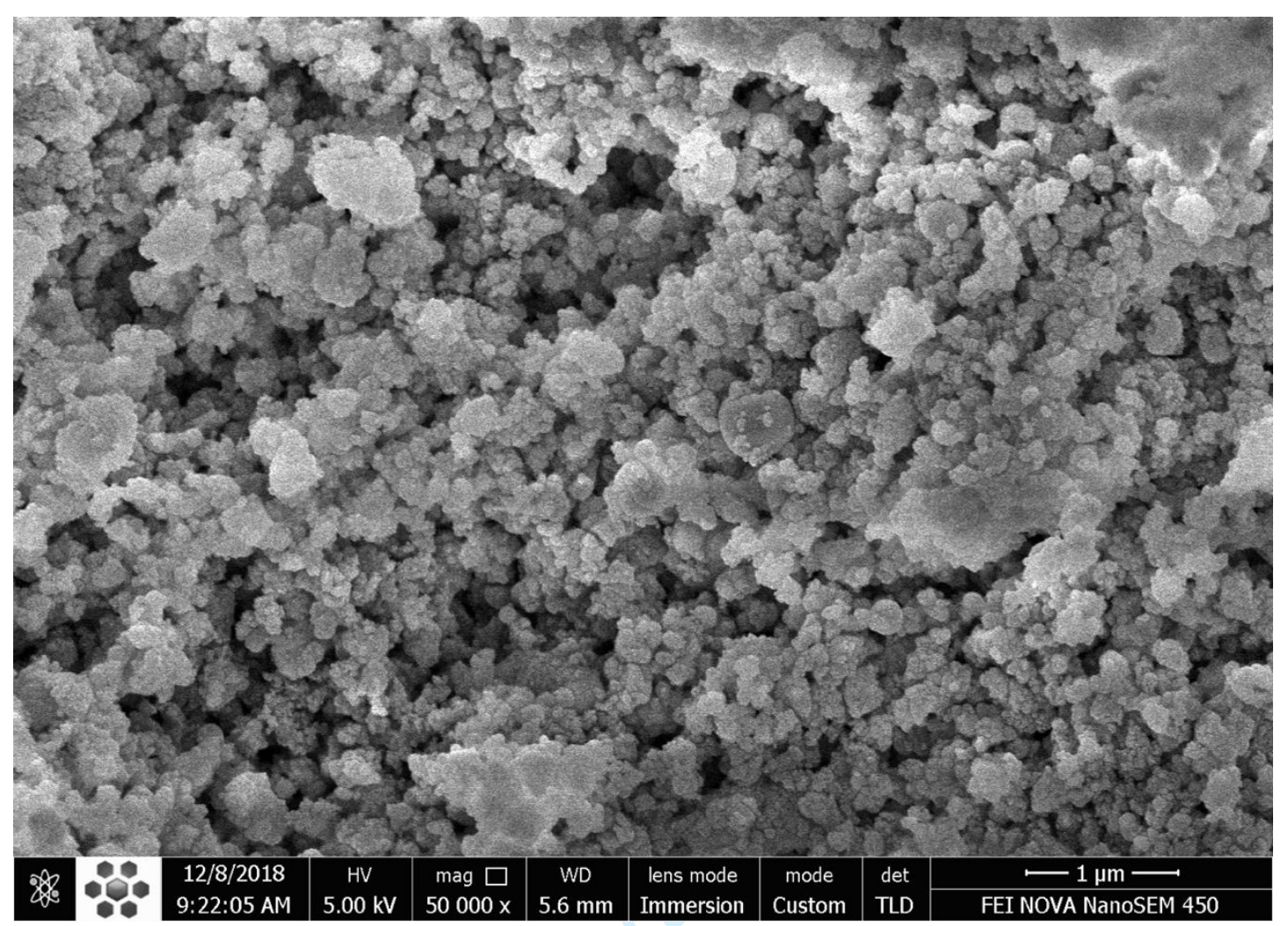

(b)

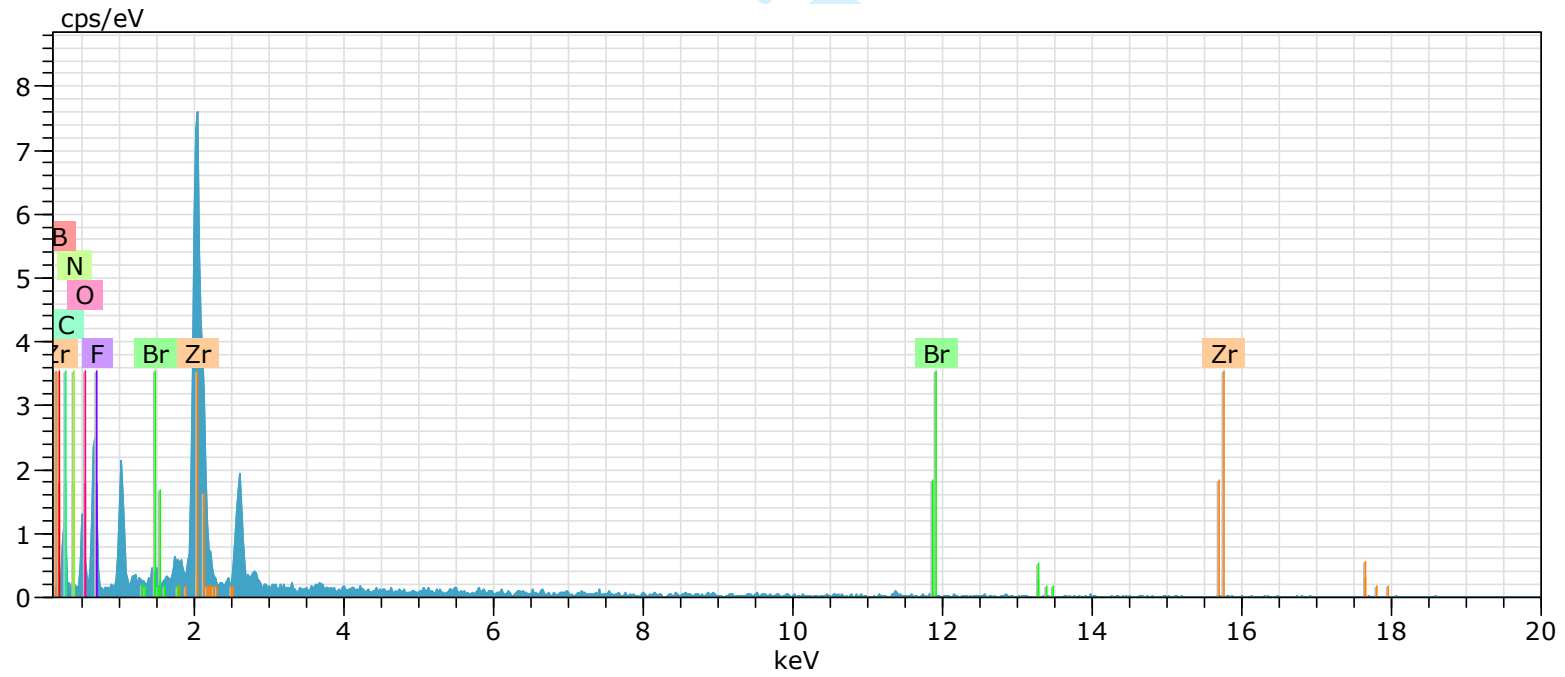

(c) 

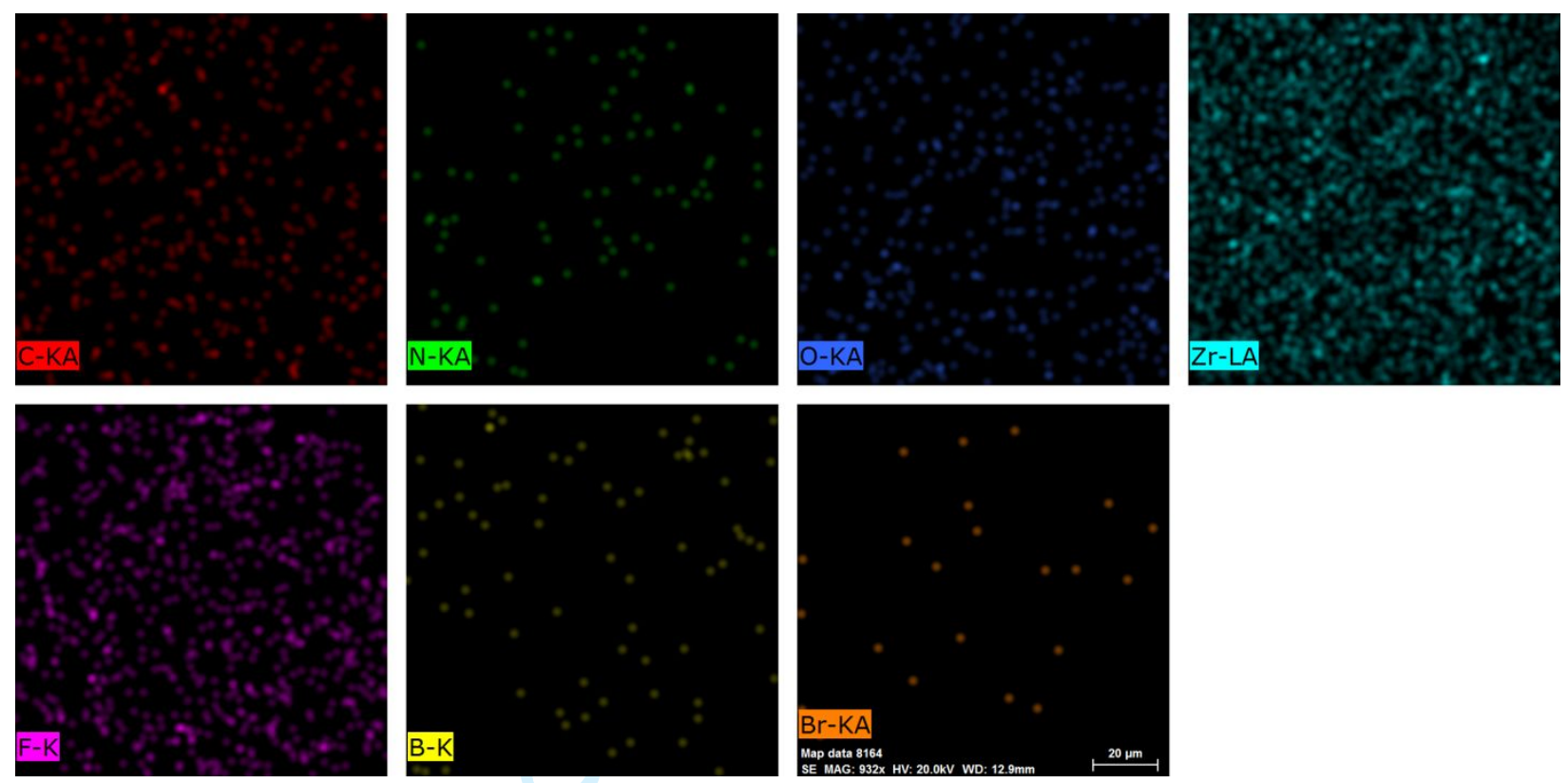

(d)

Figure 4. TEM (a) and SEM (b) images, EDS spectrum (c), and elemental mapping in selected area (d) of the UiO-66- $\mathrm{NH}_{2}-\mathrm{ILBF}_{4}^{-}$-urea.

\subsection{Synthesis of oximes using $\mathrm{UiO}-66-\mathrm{NH}_{2}-\mathrm{ILBF}_{4}^{-}$-urea heterogeneous catalyst}

A zirconium MOF with incorporated IL and urea (UiO-66- $\mathrm{NH}_{2}-\mathrm{ILBF}_{4}{ }^{-}$-urea) was used as a platform for catalyzing organic reactions. In the current work, the synthesis of oximes was selected due to the simplicity of the procedure (highly crystalline compound [40]), an efficient condensation reaction, and an interesting intermediate with broad applications. Oxime is basically an imine with a general formula: $\mathrm{RR}$ 'C $=\mathrm{NOH}$, where $\mathrm{R}$ is an alkyl and $\mathrm{R}^{\prime}$ could be hydrogen (to form aldoxime) and/or alkyl (to form ketoxime). The condensation reaction between benzaldehyde and hydroxylammonium chloride was chosen as a model reaction to examine the catalytic activity of UiO-66- $\mathrm{NH}_{2}-\mathrm{ILBF}_{4}{ }^{-}$urea as a heterogeneous catalyst. Urea acts as a basic site for catalyzing the reaction and also adjust the $\mathrm{pH}$ of the medium to neutral as $\mathrm{HCl}$ is generated from hydroxylamine hydrochloride [43]. With regards to the mechanism, the amine group of urea initially activates the oxygen of the carbonyl group (of benzaldehyde) via a hydrogen bonding and facilitates the nucleophilic addition of hydroxylamine to the carbon of the carbonyl [43]. Two hydrogen bonding donors have been proposed for urea on the carbonyl activation [58]. Oxime is finally formed by a dehydration reaction.

To optimize the reaction conditions, the effect of various reaction parameters such as type of solvent, temperature, and amount of catalyst were studied in the first stage (Table 3 ). The effect of common 
solvents such as ethanol, acetonitrile, mixture of water and ethanol, and toluene were investigated on the reaction (Table 3, entry 1-3 and 6). The results revealed that a solvent with medium polarity of is indispensable for the reaction to proceed. Ethanol was found to be the best choice for this reaction. The effect of various temperatures such as $\left(25,60\right.$ and $\left.90^{\circ} \mathrm{C}\right)$ were studied for the model reaction (Table 3, entry 4-6). In contrast to the reported results, the lower temperature $\left(25^{\circ} \mathrm{C}\right)$ showed a better result compared to the higher temperatures. When the temperature was increased from 25 to $90{ }^{\circ} \mathrm{C}$, the yield was decreased from $86 \%$ to $51 \%$ (Table 3, entry 4). It is proposed that the local motions of the linear and long alkyl group (attached to urea) increase by increasing the temperature leading to unfavorable interaction between urea and the imidazolium ring (synergic effect, discuss later). Hence, the urea (in cooperation with the IL) is not able to activate the carbonyl group of aldehydes and ketones for nucleophilic addition reaction. The effect of the catalyst amount on the reaction was also studied by varying it from $0.05-0.1 \mathrm{~g}$ (Table 3, entry 6-9), while keeping the other parameters constant. It was observed that $0.05 \mathrm{~g}$ of catalyst was sufficient for completion of the reaction. It was observed that by using a higher amount of catalyst, the yield of the reaction was not enhanced. The optimum condition was found to be $0.05 \mathrm{~g}$ of the catalyst, ethanol as a solvent, temperature at $25^{\circ} \mathrm{C}$ with a reaction time of 15 min.

Table 3. Optimization of the reaction conditions for the synthesis of oximes using UiO-66- $\mathrm{NH}_{2}$ $\mathrm{ILBF}_{4}{ }^{-}$-urea as the catalyst. ${ }^{a}$

\begin{tabular}{|l|l|l|l|l|}
\hline Entry & Solvents & Catalyst amount $(\mathrm{g})$ & Temperature $\left({ }^{\circ} \mathbf{C}\right)$ & ${\text { Yield }(\%)^{b}}^{b}$ \\
\hline 1 & Toluene & 0.05 & 25 & 43 \\
\hline 2 & Acetonitrile & 0.05 & 25 & 50 \\
\hline 3 & Ethanol $+\mathrm{H}_{2} \mathrm{O}$ & 0.05 & 25 & 68 \\
\hline 4 & Ethanol & 0.05 & 90 & 51 \\
\hline 5 & Ethanol & 0.05 & 60 & 70 \\
\hline 6 & Ethanol & 0.05 & 25 & 86 \\
\hline 7 & Ethanol & 0.04 & 25 & 80 \\
\hline 8 & Ethanol & 0.03 & 25 & 70 \\
\hline 9 & Ethanol & 0.1 & 25 & 86 \\
\hline
\end{tabular}

${ }^{a}$ Reaction conditions: benzaldehyde $(1 \mathrm{mmol})$, hydroxylammonium chloride $(1.5 \mathrm{mmol})$, solvent $(1 \mathrm{~mL})$, catalyst, reaction time (15 min).

${ }^{b}$ Isolated yield. 
To extent the current approach, a variety of substrates were used for the synthesis of different oximes. As shown in Table 4 various types of aromatic aldehydes with electron donating and withdrawing groups were successfully reacted with hydroxylamine hydrochloride and afforded the corresponding oximes in good to excellent yields. The nature of the substituents did not show a significant effect on the reaction efficiency, which is in good agreement with the results reported in the literature [72]. According to the results, hydroxy as an electron-donating group improved the reaction yield (Table 4, entry 2), while the alkyl and halide groups in the ortho position made a steric hindrance for the reaction and reduce the yield (Table 4, entries 3 and 8). Moreover, cinnamaldehyde as a non-aromatic showed a reasonable yield in the reaction (Table 4, entry 5). The nitro group in the para position (Table 4, entry 6) exhibited more deactivating effect in the condensation reaction compared to that in the meta position (Table 4, entry 7) due to an effective electron delocalization of the carbonyl group towards the nitro group in the para position. Methoxy groups in the para and meta positions showed unexpected results, compared to electron-donating and -withdrawing groups, for unknown reasons (Table 4, entries 4 and 9). On the other hand, aromatic ketones are generally less reactive in the condensation reaction compared to aromatic aldehydes due to their steric hindrance [51]. Acetophenone (Table 4, entry 10) exhibited a good yield (75\% in $25 \mathrm{~min}$ ) in comparison with the reported result with (55\% yield in $10 \mathrm{~min}$ ) using nanostructured pyrophosphate catalyst [72]. An aliphatic cyclic ketone, cyclohexanone (Table 4, entry 11), showed better results compared to aromatic ketones and comparable result with aromatic aldehydes.

Table 4. Synthesis of oximes via reaction of aldehydes and/or ketones with hydroxylammonium chloride. $^{\mathrm{a}}$

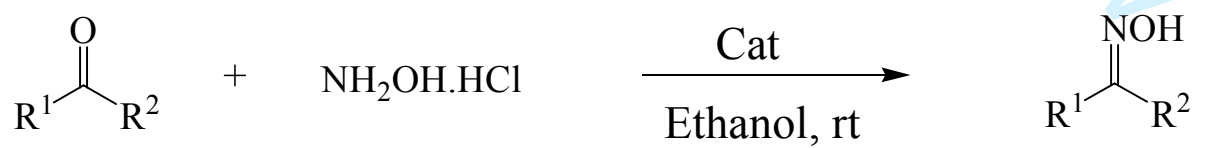

\begin{tabular}{|c|c|c|c|c|}
\hline Entry & Substrate & Time (min) & Yield $(\%)^{b}$ & Melting point $\left({ }^{\circ} \mathbf{C}\right)^{\text {Ref }}$ \\
\hline 1 & & 15 & 86 & $31-33(33-35)^{57}$ \\
\hline 2 & $\mathrm{H}$ & 25 & 92 & $55-58(57-59)^{57}$ \\
\hline
\end{tabular}




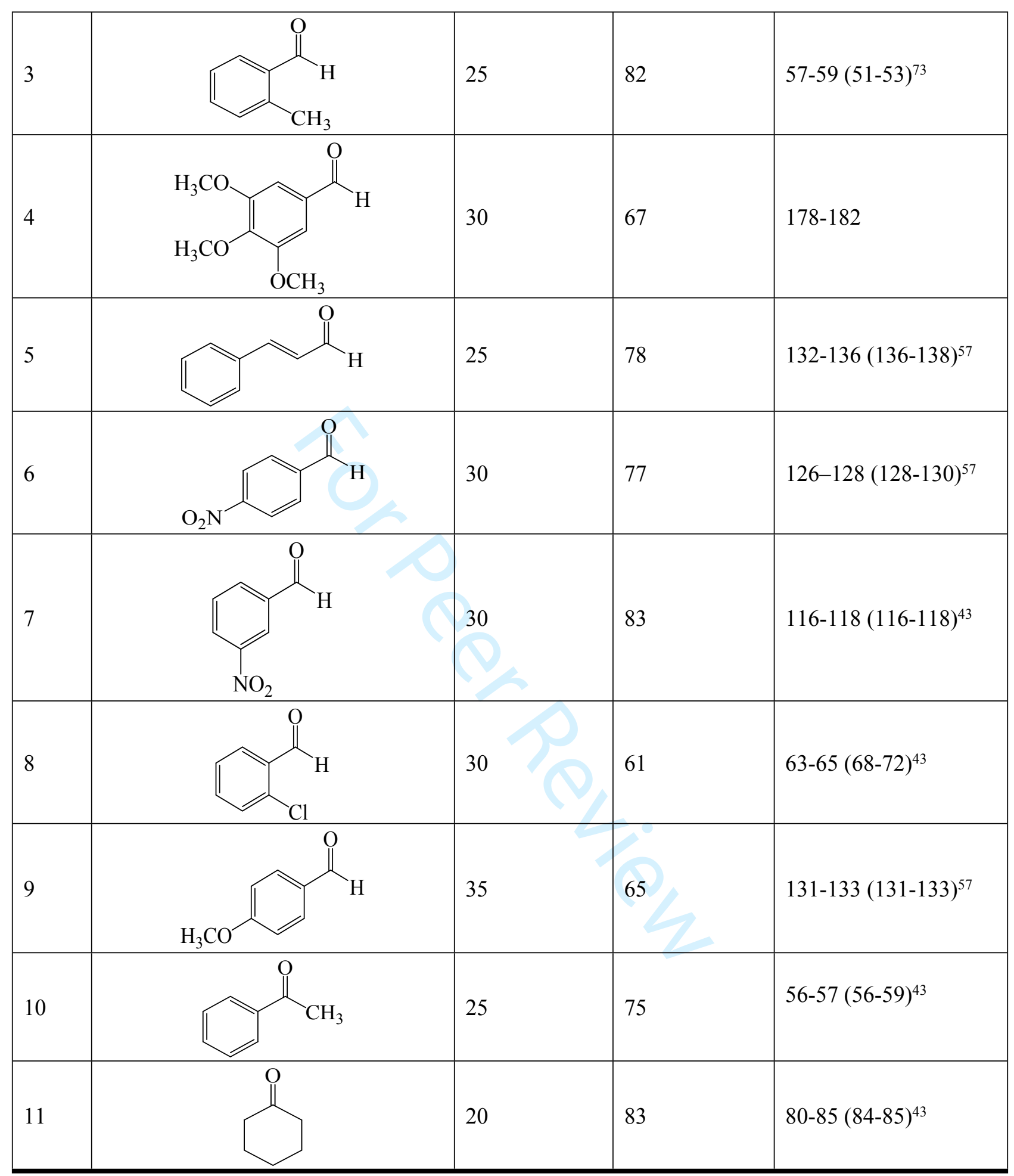

${ }^{a}$ Reaction conditions: aldehyde or ketone $(1 \mathrm{mmol})$, hydroxylammonium chloride $(1.5 \mathrm{mmol})$, ethanol $(1 \mathrm{~mL})$, UiO-66- $\mathrm{NH}_{2} \mathrm{ILBF}_{4}{ }^{-}$-urea $(0.05 \mathrm{~g})$ at $25^{\circ} \mathrm{C}$ in $15-35 \mathrm{~min}$.

${ }^{b}$ Isolated yield

The effect of anion incorporated on the IL $\left(\mathrm{BF}_{4}^{-}\right.$vs. $\left.\mathrm{Br}^{-}\right)$was also studied by keeping the other parameters such as amount of catalyst, solvent type and temperature (Table 5). By replacing $\mathrm{Br}^{-}$with 
$\mathrm{BF}_{4}^{-}$, the reaction time is reduced, and the reaction efficiency enhanced, which was consistent with the reported results; the IL of $\mathrm{bmiBF}_{4}$ has showed higher yields compared to bmiCl [55]. Moreover, $\mathrm{Br}^{-}$has a hydrophilic nature and is miscible in highly polar solvents, thus the ion solvation restricts the activity of the supported IL, in contrast $\mathrm{BF}_{4}^{-}$exhibit hydrophobicity and immiscibility in aqueous media [74]. The effect of the substrate (i.e. UiO-66- $\mathrm{NH}_{2}$ ) was examined and the result showed a medium activity probably due to high surface area and available basic sites on the MOF. In addition, the activity of the ionic liquid (e.g. $\mathrm{ILBr}^{-}, \mathrm{IL}_{-} \mathrm{BF}_{4}^{-}$) and urea in homogenous phase were investigated. ILs exhibited a limited effect on the activation of the carbonyl groups and deprotonation of hydroxyl amine by $\mathrm{Br}^{-}$and $\mathrm{BF}_{4}^{-}$. Urea as a base was not effective in the homogeneous phase, while by grafting to the IL and the MOF, their synergic effects may promote the hydrogen-bonding donation of the urea in heterogeneous phase. A similar synergic activation has been found for (2hydroxyethyl)trimethylammonium in choline chloride/urea system supported on molecular sieves for the $\mathrm{CO}_{2}$ cyclization with epoxides [75].

Table 5. The catalytic activity of the catalyst, the support and the IL in homogeneous phase. ${ }^{a}$

\begin{tabular}{|l|c|c|}
\hline Catalyst & Time (min) & Yield (\%) $^{\boldsymbol{b}}$ \\
\hline $\mathrm{UiO}-66-\mathrm{NH}_{2}-\mathrm{ILBF}_{4}^{-}$-urea & 15 & 86 \\
\hline $\mathrm{UiO}-66-\mathrm{NH}_{2}-\mathrm{ILBr}^{-}$-urea & 20 & 70 \\
\hline $\mathrm{UiO}^{-66-\mathrm{NH}_{2}}$ & 30 & 43 \\
\hline $\mathrm{ILBF}_{4}^{-}$ & 35 & 33 \\
\hline $\mathrm{ILBr}^{-}$ & 35 & 20 \\
\hline urea & 35 & Trace \\
\hline
\end{tabular}

${ }^{a}$ Reaction conditions: benzaldehyde $(1 \mathrm{mmol})$, hydroxylammonium chloride $(1.5 \mathrm{mmol})$, ethanol $(1 \mathrm{~mL})$, temperature $\left(25^{\circ} \mathrm{C}\right)$, and catalyst or $\mathrm{UiO}-66-\mathrm{NH}_{2}$ or IL $(0.05 \mathrm{~g})$.

${ }^{b}$ Isolated yield.

\section{Catalyst recycling and stability}

The recyclability and reusability of the catalyst were studied for the condensation reaction using a model reaction between benzaldehyde with hydroxylammonium chloride (Figure 5). After each cycle, the catalyst was reactivated by centrifugation, washing with water and ethanol (to remove the residual starting materials on the catalyst surface and pores), and drying at $60^{\circ} \mathrm{C}$ in an oven overnight. The catalyst was successfully recycled and reused 5 times without significant loss of the performance. The slight reduction in catalyst activity might be related to the partial blocking of the pores by trapped starting materials or product $[76,77]$. The BET surface area and total pore volume of the reused 
catalyst were reduced ( $c f$. the fresh catalyst) and found to be $427 \mathrm{~m}^{2} \mathrm{~g}^{-1}$ and $0.34 \mathrm{~cm}^{3} \mathrm{~g}^{-1}$, respectively, although a slight increase in pore size $\left(1.0 \mathrm{~nm}\right.$ ) was observed (Table 1). The $\mathrm{N}_{2}$ adsorption-desorption isotherm and pore size distribution of the reused catalyst can be found in Figure 1c,d.

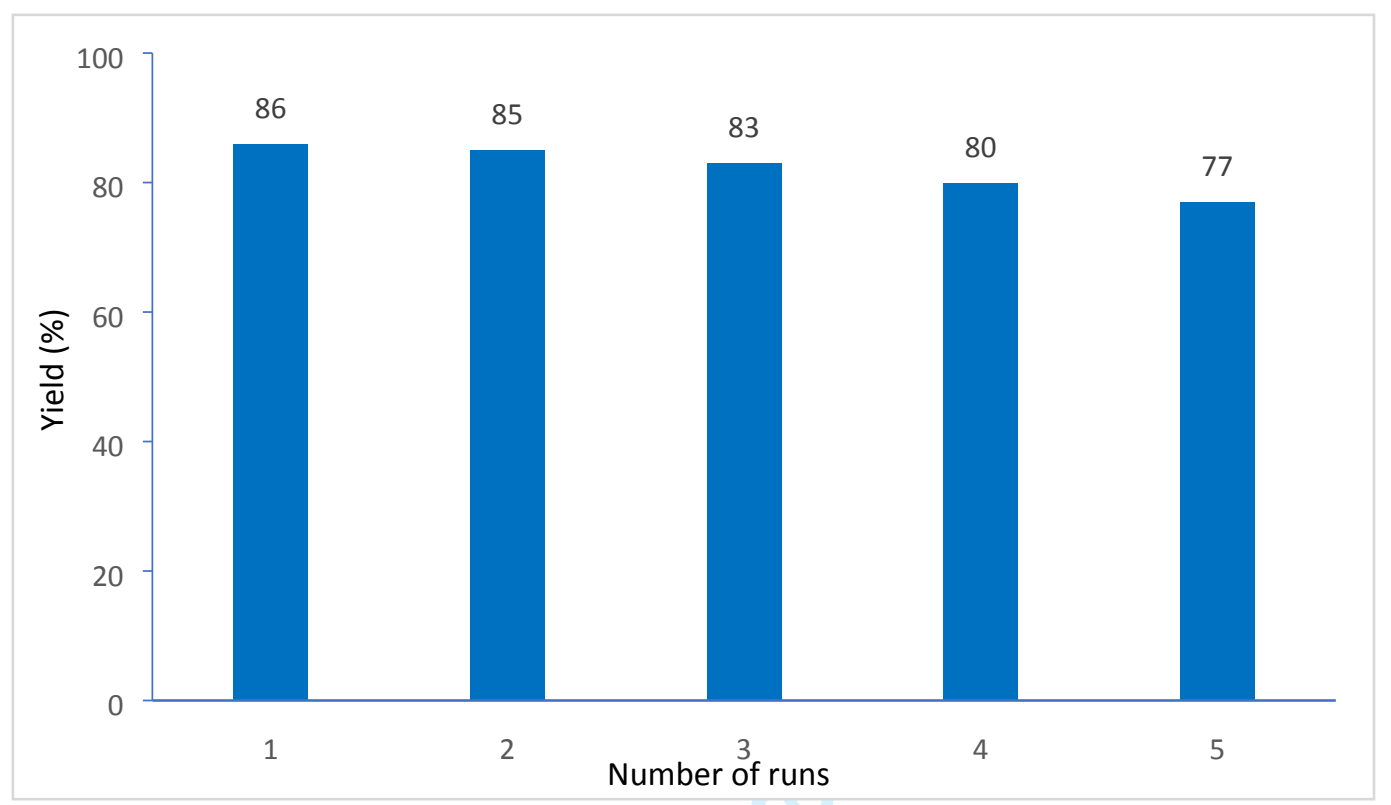

Figure 5. Reusability of the catalyst for the synthesis of oxime.

The catalyst stability was investigated by XRD, FTIR, electron microscopy, and elemental analysis. XRD pattern and the FT-IR spectrum of the reused UiO-66- $\mathrm{NH}_{2}-\mathrm{ILBF}_{4}{ }^{-}$-urea show similar patterns (Figure 1a,b) to those in fresh catalyst, indicating that the catalyst is almost stable under reaction conditions after five times of recycling and reusing. Furthermore, the morphology and the chemical composition of the UiO-66- $\mathrm{NH}_{2}-\mathrm{ILBF}_{4}^{-}$-urea (after five times of reusing) were studied by FE-SEM (Figure 6) and elemental analysis/mapping (Figure S8 and S9, Supporting Information). The results showed a slight change in the morphology and similar composition for the recycled catalyst in comparison with those for the fresh catalyst. An atomic percentage for the corresponding elements in the recycled catalyst was found to be $\mathrm{Zr}(4.4 \%), \mathrm{O}(18.6 \%), \mathrm{C}(39.1 \%), \mathrm{N}(5.2 \%), \mathrm{B}(9.3 \%)$, and $\mathrm{F}$ (23.3\%). A slight reduction in the content of $\mathrm{B}$ and $\mathrm{F}$ (corresponding to $\mathrm{BF}_{4}^{-}$) caused negligible leaching for the reused catalyst after five successive recycling. Furthermore, the activity of the extracted catalyst after hot filtration $\left(70{ }^{\circ} \mathrm{C}\right.$ in $\mathrm{EtOH}$ for $2 \mathrm{~h}$ ) was reduced to a yield of $80 \%$, which could be related to leaching of $\mathrm{BF}_{4}^{-}$at an elevated temperature. Consequently, the catalyst can be easily recycled and reused several times with a reasonable stability. 


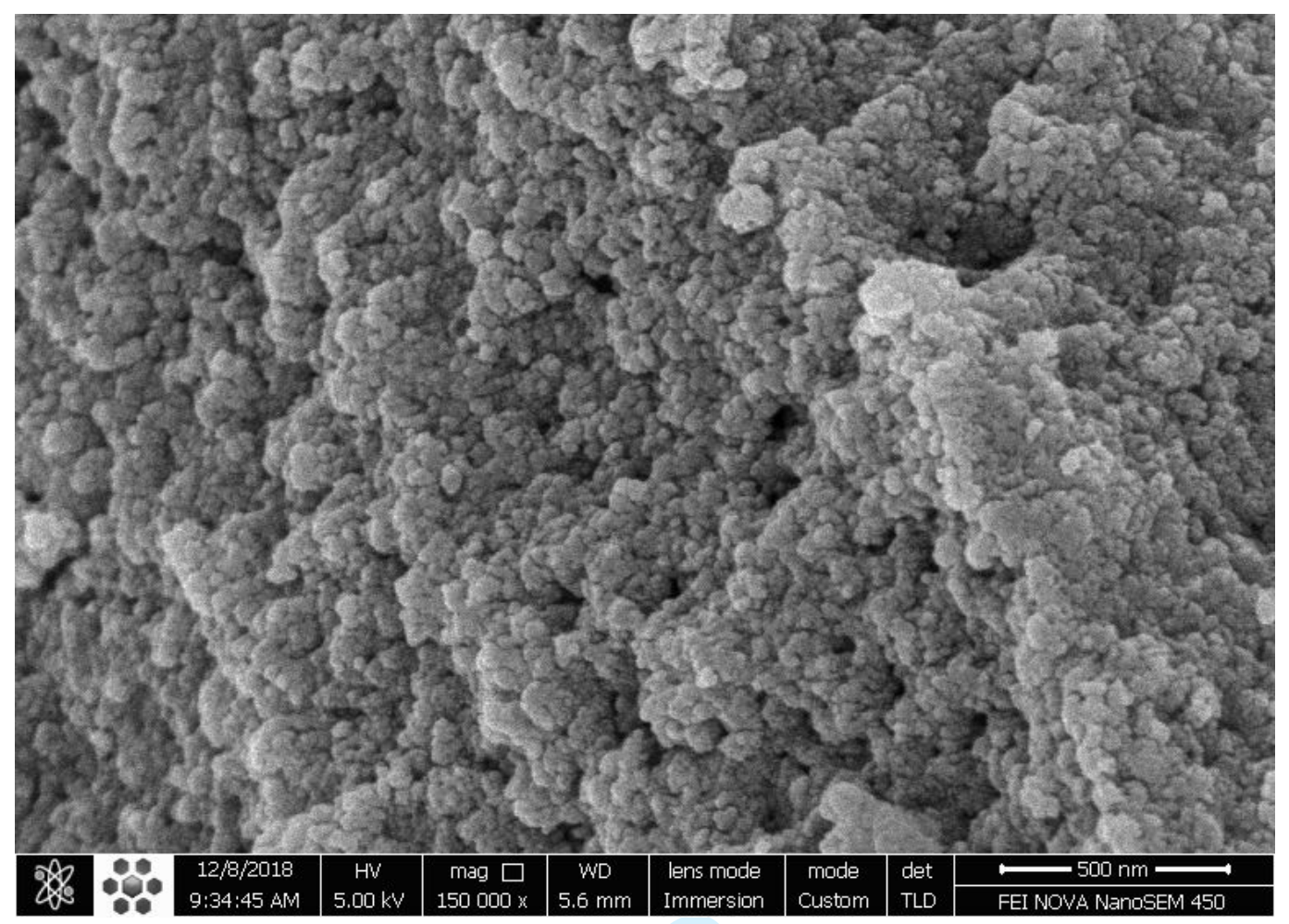

Figure 6. FE-SEM image of the catalyst after five times reuse.

Different types of acidic (Brønsted, Lewis, and solid acids, entries 1-11, Table 6) and basic (metal hydroxide and organic bases, entries 12-15) conditions were used for the synthesis of oximes. Organic and polar solvents and also solventless conditions were suitable media for the syntheses. Microwave (MW) and ultrasonic (US) irradiations, reflux, and grinding were applied to accelerate the reactions. Ionic liquids were also employed as a catalyst or reaction medium. Major environmental and economic concerns on the reported catalytic systems are catalyst recoverability and reusability, therefore, integration of catalysts to solid porous supports is encouraging. The current catalytic system, a heterogeneous basic catalyst, showed comparable results in terms of yield and reaction conditions (e.g. temperature and time), and superior recyclability, reusability, and robustness compared to the reported systems.

Table 6. Synthesis of oximes via reaction of benzaldehydes with hydroxylammonium chloride $\left(\mathrm{NH}_{2} \mathrm{OH} . \mathrm{HCl}\right)$ using different catalytic systems.

\begin{tabular}{|l|l|l|l|l|l|}
\hline Entry & Catalytic systems & Reaction conditions & Time (min) & Yield (\%) & Ref. \\
\hline 1 & $\mathrm{TiO}_{2} / \mathrm{SO}_{4}{ }^{2-}(0.05 \mathrm{~g})$ & $130{ }^{\circ} \mathrm{C}$, solventless & 1 & 100 & 51 \\
\hline 2 & $\mathrm{Na}_{2} \mathrm{SO}_{4}(0.1 \mathrm{mmol})$ & $\mathrm{US}\left(25-35^{\circ} \mathrm{C}\right), \mathrm{EtOH}$ & 5 & 88 & 43 \\
\hline
\end{tabular}




\begin{tabular}{|c|c|c|c|c|c|}
\hline 3 & $\begin{array}{l}\mathrm{HCl} \text { (2 drops), } \mathrm{K}_{2} \mathrm{CO}_{3}(10 \%), \mathrm{pH} \\
10\end{array}$ & $\mathrm{US}, \mathrm{H}_{2} \mathrm{O}$ & immediately & 91 & 78 \\
\hline 4 & $\mathrm{BF}_{3} \cdot \mathrm{Et}_{2} \mathrm{O}(10 \mathrm{~mol} \%)$ & Reflux, $\mathrm{CH}_{3} \mathrm{OH}$ & $3.5(\mathrm{~h})$ & $87^{\mathrm{a}}$ & 44 \\
\hline 5 & $\mathrm{BF}_{3} \cdot \mathrm{Et}_{2} \mathrm{O}(10 \mathrm{~mol} \%)$ & $\mathrm{MW}, \mathrm{CH}_{3} \mathrm{OH}$ & 6 & $95^{\mathrm{a}}$ & 44 \\
\hline 6 & Silica gel 60, 230-400 mesh (1 g) & $\begin{array}{l}\text { MW }(800 \mathrm{~W}, 80-90 \\
\left.{ }^{\circ} \mathrm{C}\right) \text {, solventless }\end{array}$ & 3 & 100 & 40 \\
\hline 7 & Wet basic $\mathrm{Al}_{2} \mathrm{O}_{3}$ (1.5 equiv.) & MW, solventless & 5 & 79 & 53 \\
\hline 8 & Molecular sieves $4 \AA$ (2.5 g) & grinding & 30 & 60 & 53 \\
\hline 9 & $\mathrm{Na}_{2} \mathrm{CaP}_{2} \mathrm{O}_{7}$ nanostructure $(0.1 \mathrm{~g})$ & $\begin{array}{l}\text { MW }\left(400 \mathrm{~W}, 80{ }^{\circ} \mathrm{C}\right), \\
\text { solventless }\end{array}$ & 4 & 82 & 72 \\
\hline 10 & $\mathrm{Na}_{2} \mathrm{CaP}_{2} \mathrm{O}_{7}$ nanostructure $(0.1 \mathrm{~g})$ & $80^{\circ} \mathrm{C}$, solventless & 10 & 83 & 72 \\
\hline 11 & $\begin{array}{l}\mathrm{Na}_{12}\left[\mathrm{WZn}_{3}\left(\mathrm{H}_{2} \mathrm{O}\right)_{2}\left(\mathrm{ZnW}_{9} \mathrm{O}_{34}\right)_{2}\right] \\
(0.01 \mathrm{mmol})\end{array}$ & $\begin{array}{lll}\mathrm{H}_{2} \mathrm{O}_{2} & (27 \%), & \mathrm{NH}_{3} \\
(25 \%), & \mathrm{H}_{2} \mathrm{O}, \mathrm{rt}\end{array}$ & $6(\mathrm{~h})$ & 95 & 52 \\
\hline 12 & $\mathrm{NaOH}$ (1.2 mol) & $\begin{array}{l}\text { grinding, } \mathrm{CH}_{3} \mathrm{OH}(2-4 \\
\text { drops), } \mathrm{rt}\end{array}$ & 2 & $71^{\mathrm{b}}$ & 54 \\
\hline 13 & $\mathrm{DABCO}^{\mathrm{c}}(1 \mathrm{mmol})$ & $\begin{array}{l}\text { Grinding \& MW (900 } \\
\text { W), solventless }\end{array}$ & $70(s)$ & 98 & 57 \\
\hline 14 & $\left(\mathrm{PhCH}_{2}\right)_{3} \mathrm{~N}(1 \mathrm{mmol})$ & $\begin{array}{l}\text { Grinding \& MW (900 } \\
\text { W), solventless }\end{array}$ & 90 & 98 & 57 \\
\hline 15 & Glycine $(0.5 \mathrm{mmol})$ & DMF, rt & $5(\mathrm{~h})$ & $96^{\mathrm{d}}$ & 59 \\
\hline 16 & {$[\mathrm{bmIm}] \mathrm{OH}(2 \mathrm{mmol})$} & US, EtOH, rt & 5 & 91 & 56 \\
\hline 17 & $\mathrm{bmiBF}_{4}(2 \mathrm{mmol})$ & $\mathrm{rt}$ & 30 & $95^{\mathrm{d}}$ & 55 \\
\hline 18 & UiO-66-NH ${ }_{2}-\mathrm{ILBF}_{4}^{-}$-urea $(0.05 \mathrm{~g})$ & $\mathrm{EtOH}, \mathrm{rt}$ & 15 & 86 & $\begin{array}{l}\text { This } \\
\text { work }\end{array}$ \\
\hline
\end{tabular}

${ }^{\mathrm{a}} \mathrm{CH}_{3} \mathrm{CONHOH}$ was used instead of $\mathrm{NH}_{2} \mathrm{OH} . \mathrm{HCl}$

b2-Hydroxybenzaldehyde as a precursor

c1,4-Diazabicyclo[2.2.2] octane

${ }^{\mathrm{d} C y c l o h e x a n e}$ as a precursor

\section{Conclusion}

A robust supported ionic liquid system is introduced for the organic synthesis of oximes. In the design strategy, the basic heterogeneous catalyst was successfully prepared by employing a chemical/thermal stable $\mathrm{Zr}$-based MOF, UiO-66- $\mathrm{NH}_{2}$ as a support. The MOF was initially modified with an ionic liquid to make a supported ionic liquid (SIL), followed by covalent anchoring of urea to the cation moiety of IL to form a TSIL. The as-prepared catalyst was examined for the synthesis of oximes. UiO-66- $\mathrm{NH}_{2}-\mathrm{ILBF}_{4}{ }^{-}$-urea catalyst showed excellent performance in the reaction of various 
aldehydes and ketones with hydroxylammonium chloride in good yields. Ethanol was the best candidate as a solvent in the current method. The catalyst was successfully recycled and reused for several times without significant loss of activity. Due to high specific area and large porosity of the MOFs, they can be extensively employed in various catalytic reactions with efficient performance. Moreover, a large number of available pores in MOFs can be a suitable host for ionic liquids to produce a large variety of heterogeneous catalysts. More efforts can be helpful to design new taskspecific ILs attached to MOF using basic groups (e.g. thiourea, polyamines, etc.) and/or acidic groups (e.g. $\left.-\mathrm{SO}_{3} \mathrm{H}\right)$.

\section{Acknowledgements}

M. Jafarzadeh is thankful to Razi University for the partial financial supports, and Prof. Kim Daasbjerg and Monica Rohde Madsen (Aarhus University, Denmark) for XPS analysis.

\section{References}

[1] V. Campisciano, F. Giacalone, M. Gruttadauria, Supported ionic liquids: A versatile and useful class of materials, Chem. Rec. 2017, 17, 918-938.

[2] B. V. Romanovsky, I. G. Tarkhanova, Supported ionic liquids in catalysis, Russ. Chem. Rev. 2017, 86, 444-458.

[3] A. Riisager, B. Jørgensen, P. Wasserscheid, R. Fehrmann, First application of supported ionic liquid phase (SILP) catalysis for continuous methanol carbonylation, Chem. Commun. 2006, 994996.

[4] J. Joni, M. Haumann, P. Wasserscheid, Development of a supported ionic liquid phase (SILP) catalyst for slurry-phase Friedel-Crafts alkylations of cumene, Adv. Synth. Catal. 2009, 351, 423431.

[5] J. Lemus, J. Palomar, M. A. Gilarranz, J. J. Rodriguez, Characterization of supported ionic liquid phase (SILP) materials prepared from different supports, Adsorption 2011, 17, 561-571.

[6] S. More, S. Jadhav, R. Salunkhe, A. Kumbhar, Palladium supported ionic liquid phase catalyst (Pd@SILP-PS) for room temperature Suzuki-Miyaura cross-coupling reaction, Mol. Catal. 2017, 442, 126-132.

[7] B. Xin, J. Hao, Imidazolium-based ionic liquids grafted on solid surfaces, Chem. Soc. Rev. 2014, $43,7171-7187$. 
[8] A. Riisager, R. Fehrmann, M. Haumann, P. Wasserscheid, Supported ionic liquid phase (SILP) catalysis: An innovative concept for homogeneous catalysis in continuous fixed-bed reactors, Eur. J. Inorg. Chem. 2006, 695-706.

[9] Q. Zhang, S. Zhang, Y. Deng, Recent advances in ionic liquid catalysis, Green Chem. 2011, 13, 2619-2637.

[10] H. Hagiwara, M. Sekifuji, T. Hoshi, K. Qiao, C. Yokoyama, Synthesis of bis(indolyl)methanes catalyzed by acidic ionic liquid immobilized on silica (ILIS), Synlett 2007, 1320-1322.

[11] Y. Gu, G. Li, Ionic liquids-based catalysis with solids: State of the art, Adv. Synth. Catal. 2009, $351,817-847$.

[12] S.-G. Lee, Functionalized imidazolium salts for task-specific ionic liquids and their applications, Chem. Commun. 2006, 1049-1063.

[13] H. Olivier-Bourbigou, L. Magna, D. Morvan, Ionic liquids and catalysis: Recent progress from knowledge to applications, Appl. Catal. A 2010, 373, 1-56.

[14] A. D. Sawant, D. G. Raut, N. B. Darvatkar, M. M. Salunkhe, Recent developments of taskspecific ionic liquids in organic synthesis, Green Chem. Lett. Rev. 2011, 4, 41-54.

[15] P. Izák, F. D. Bobbink, M. Hulla, M. Klepic, K. Friess, S. Hovorka, P. J. Dyson, Catalytic ionicliquid membranes: The convergence of ionic-liquid catalysis and ionic-liquid membrane separation technologies, ChemPlusChem 2018, 83, 7-18.

[16] Q. Zhang, S. Zhang, Y. Deng, Recent advances in ionic liquid catalysis, Green Chem. 2011, 13, 2619-2637.

[17] C. P. Mehnert, Supported ionic liquid catalysis, Chem. Eur. J. 2005, 11, 50-56.

[18] C. P. Mehnert, R. A. Cook, N. C. Dispenziere, M. Afeworki, Supported ionic liquid catalysis A new concept for homogeneous hydroformylation catalysis, J. Am. Chem. Soc. 2002, 124, 1293212933.

[19] H. Li, P. S. Bhadury, B. Song, S. Yang, Immobilized functional ionic liquids: efficient, green, and reusable catalysts, RSC Adv. 2012, 2, 12525-12551.

[20] Q.-X. Luo, B.-W. An, M. Ji, J. Zhang, Hybridization of metal-organic frameworks and taskspecific ionic liquids: fundamentals and challenges, Mater. Chem. Front. 2018, 2, 219-234.

[21] Y. Takashima, M. Yokoyama, A. Horikoshi, Y. Sato, T. Tsuruoka, K. Akamatsu, Ionic liquid/metal-organic framework hybrid generated by ion-exchange reaction: synthesis and unique catalytic activity, New J. Chem. 2017, 41, 14409-14413. 
[22] D. Farrusseng, S. Aguado, C. Pinel, Metal-organic frameworks: Opportunities for catalysis, Angew. Chem. Int. Ed. 2009, 48, 7502-7513.

[23] H. He, J. A. Perman, G. Zhu, S. Ma, Metal-organic frameworks for $\mathrm{CO}_{2}$ chemical transformations, Small 2016, 12, 6309-6324.

[24] L. Jiao, J. Y. R. Seow, W. S. Skinner, Z. U. Wang, H.-L. Jiang, Metal-organic frameworks: Structures and functional applications, Mater. Today 2019, 27, 43-68.

[25] Q.-X. Luo, M. Ji, M.-H. Lu, C. Hao, J.-S. Qiu, Y.-Q. Li, Organic electron-rich N-heterocyclic compound as a chemical bridge: building a Brönsted acidic ionic liquid confined in MIL-101 nanocages, J. Mater. Chem. A 2013, 1, 6530-6534.

[26] Q.-X. Luo, M. Ji, S.-E. Park, C. Hao, Y.-Q. Li, PdCl 2 immobilized on metal-organic framework CuBTC with the aid of ionic liquids: enhanced catalytic performance in selective oxidation of cyclohexene, RSC Adv. 2016, 6, 33048-33054.

[27] S. Abednatanzi, K. Leus, P. Gohari Derakhshandeh, F. Nahra, K. De Keukeleere, K. Van Hecke, I. Van Driessche, A. Abbasi, S. P. Nolan, P. Van Der Voort, POM@IL-MOFs - inclusion of POMs in ionic liquid modified MOFs to produce recyclable oxidation catalysts, Catal. Sci. Technol. 2017, 7, 1478-1487.

[28] S. Abednatanzi, A. Abbasi, M. Masteri-Farahani, Immobilization of catalytically active polyoxotungstate into ionic liquid-modified MIL-100(Fe): A recyclable catalyst for selective oxidation of benzyl alcohol, Catal. Commun. 2017, 96, 6-10.

[29] N. A. Khan, Z. Hasan, S. H. Jhung, Ionic liquids supported on metal-organic frameworks: Remarkable adsorbents for adsorptive desulfurization, Chem. Eur. J. 2014, 20, 376-380.

[30] J. Wu, Y. Gao, W. Zhang, Y. Tan, A. Tang, Y. Men, B. Tang, Deep desulfurization by oxidation using an active ionic liquid-supported $\mathrm{Zr}$ metal-organic framework as catalyst, Appl. Organometal. Chem. 2015, 29, 96-100.

[31] Q.-X. Luo, X.-D. Song, M. Ji, S.-E. Park, C. Hao, Y.-Q. Li, Molecular size- and shape-selective Knoevenagel condensation over microporous $\mathrm{Cu}_{3}(\mathrm{BTC})_{2}$ immobilized amino-functionalized basic ionic liquid catalyst, Appl. Catal. A 2014, 478, 81-90.

[32] J. Tharun, K.-M. Bhin, R. Roshan, D. W. Kim, A. C. Kathalikkattil, R. Babu, H. Y. Ahn, Y. S. Won, D.-W. Park, Ionic liquid tethered post functionalized ZIF-90 framework for the cycloaddition of propylene oxide and $\mathrm{CO}_{2}$, Green Chem. 2016, 18, 2479-2487.

[33] L.-G. Ding, B.-J. Yao, W.-L. Jiang, J.-T. Li, Q.-J. Fu, Y.-A. Li, Z.-H. Liu, J.-P. Ma, Y.-B. Dong, Bifunctional imidazolium-based ionic liquid decorated UiO-67 type MOF for selective $\mathrm{CO}_{2}$ 
adsorption and catalytic property for $\mathrm{CO}_{2}$ cycloaddition with epoxides, Inorg. Chem. 2017, 56, $2337-2344$.

[34] D. Ma, B. Li, K. Liu, X. Zhang, W. Zou, Y. Yang, G. Li, Z. Shi, S. Feng, Bifunctional MOF heterogeneous catalysts based on the synergy of dual functional sites for efficient conversion of $\mathrm{CO}_{2}$ under mild and co-catalyst free conditions, J. Mater. Chem. A 2015, 3, 23136-23142.

[35] Z. Wu, C. Chen, H. Wan, L. Wang, Z. Li, B. Li, Q. Guo, G. Guan, Fabrication of magnetic $\mathrm{NH}_{2}$-MIL-88B (Fe) confined Brønsted ionic liquid as an efficient catalyst in biodiesel synthesis, Energy Fuels 2016, 30, 10739-10746.

[36] S. H. Yang, S. Chang, Highly efficient and catalytic conversion of aldoximes to nitriles, Org. Lett. 2001, 3, 4209-4211.

[37] S. Park, Y.-A. Choi, H. Han, S. H. Yang, S. Chang, Rh-Catalyzed one-pot and practical transformation of aldoximes to amides, Chem. Commun. 2003, 1936-1937.

[38] H.-G. Peng, L. Xu, H. Wu, K. Zhang, P. Wu, One-pot synthesis of benzamide over a robust tandem catalyst based on center radially fibrous silica encapsulated TS-1, Chem. Commun. 2013, 49, 2709-2711.

[39] S. K. Klitgaard, K. Egeblad, U. V. Mentzel, A. G. Popov, T. Jensen, E. Taarning, I. S. Nielsen, C. H. Christensen, Oxidations of amines with molecular oxygen using bifunctional gold-titania catalysts, Green Chem. 2008, 10, 419-423.

[40] A. R. Hajipour, S. E. Mallakpour, G. Imanzadeh, A rapid and convenient synthesis of oximes in dry media under microwave irradiation, J. Chem. Res. (S) 1999, 228-229.

[41] A. R. Hajipour, S. E. Mallakpour, S. Khoee, An easy and fast method for conversion of oximes to the corresponding carbonyl compounds under microwave irradiation, Synth. Commun. 2002, 32, $9-15$.

[42] V. Y. Kukushkin, A. J. L. Pombeiro, Oxime and oximate metal complexes: unconventional synthesis and reactivity, Coord. Chem. Rev. 1999, 181, 147-175.

[43] J.-T. Li, X.-L. Li, T.-S. Li, Synthesis of oximes under ultrasound irradiation, Ultrason. Sonochem. 2006, 13, 200-202.

[44] M. Sridhar, C. Narsaiah, J. Raveendra, G. K. Reddy, M. K. K. Reddy, B. C. Ramanaiah, Efficient microwave-assisted synthesis of oximes from acetohydroxamic acid and carbonyl compounds using $\mathrm{BF}_{3} . \mathrm{OEt}_{2}$ as the catalyst, Tetrahedron Lett. 2011, 52, 4701-4704. 
[45] Q. Sha, Y. Wei, Base and solvent mediated decomposition of tosylhydrazones: highly selective synthesis of N-alkyl substituted hydrazones, dialkylidenehydrazines, and oximes, Tetrahedron 2013, 69, 3829-3835.

[46] J. Yu, M. Lu, Copper(II)-promoted direct conversion of methylarenes into aromatic oximes, Org. Biomol. Chem. 2015, 13, 7397-7401.

[47] J. Yu, Y. Jin, M. Lu, 3-Methyl-4-oxa-5-azahomoadamantane as an organocatalyst for the aerobic oxidation of primary amines to oximes in water, Adv. Synth. Catal. 2015, 357, 1175-1180.

[48] X. Xue, F. Song, B. Ma, Y. Yu, C. Li, Y. Ding, Selective ammoximation of ketones and aldehydes catalyzed by a trivanadium-substituted polyoxometalate with $\mathrm{H}_{2} \mathrm{O}_{2}$ and ammonia, Catal. Commun. 2013, 33, 61-65.

[49] S. Xing, Q. Han, Z. Shi, S. Wang, P. P. Yang, Q. Wu, M. Li, A hydrophilic inorganic framework based on a sandwich polyoxometalate: unusual chemoselectivity for aldehydes/ketones with in situ generated hydroxylamine, Dalton Trans. 2017, 46, 11537-11541.

[50] K. Hyodo, K. Togashi, N. Oishi, G. Hasegawa, K. Uchida, Brønsted acid catalyzed transoximation reaction: synthesis of aldoximes and ketoximes without use of hydroxylamine salts, Green Chem. 2016, 18, 5788-5793.

[51] J.-J. Guo, T.-S. Jin, S.-L. Zhang, T.-S. Li, $\mathrm{TiO}_{2} / \mathrm{SO}_{4}{ }^{2-}$ : an efficient and convenient catalyst for preparation of aromatic oximes, Green Chem. 2001, 3, 193-195.

[52] D. Sloboda-Rozner, R. Neumann, Aqueous biphasic catalysis with polyoxometalates: Oximation of ketones and aldehydes with aqueous ammonia and hydrogen peroxide, Green Chem. 2006, 8, 679681.

[53] G. L. Kad, M. Bhandari, J. Kaur, R. Rathee, J. Singh, Solventless preparation of oximes in the solid state and via microwave irradiation, Green Chem. 2001, 3, 275-277.

[54] C. B. Aakeröy, A. S. Sinha, K. N. Epa, C. L. Spartz, J. Desper, A versatile and green mechanochemical route for aldehyde-oxime conversions, Chem. Commun. 2012, 48, 11289-11291. [55] R. X. Ren, W. Ou, Preparation of cyclic ketoximes using aqueous hydroxylamine in ionic liquids, Tetrahedron Lett. 2001, 42, 8445-8446.

[56] H. Zang, M. Wang, B.-W. Cheng, J. Song, Ultrasound-promoted synthesis of oximes catalyzed by a basic ionic liquid [bmIm]OH, Ultrason. Sonochem. 2009, 16, 301-303.

[57] A. R. Hajipour, F. Rafiee, A. E. Ruoho, A rapid and convenient method for the synthesis of aldoximes under microwave irradiation using in situ generated ionic liquids, J. Iran. Chem. Soc. 2010, 7, 114-118. 
[58] M. S. Taylor, E. N. Jacobsen, Asymmetric catalysis by chiral hydrogen-bond donors, Angew. Chem. Int. Ed. 2006, 45, 1520-1543.

[59] M. Maheswara, V. Siddaiah, K. Gopalaiah, V. M. Rao, C. V. Rao, A simple and effective glycine-catalysed procedure for the preparation of oximes, J. Chem. Res. 2006, 362-363.

[60] J. Vitz; D. H. Mac; S. Legoupy, Ionic liquid supported tin reagents for Stille cross coupling reactions, Green Chem. 2007, 9, 431-433.

[61] Y. Zhang, B. Zhen, H. Li, Y. Feng, Basic ionic liquid as catalyst and surfactant: green synthesis of quinazolinone in aqueous media, RSC Adv. 2018, 8, 36769-36774.

[62] M. Kandiah, M. H. Nilsen, S. Usseglio, S. Jakobsen, U. Olsbye, M. Tilset, C. Larabi, E. A. Quadrelli, F. Bonino, K. P. Lillerud, Synthesis and stability of tagged UiO-66 Zr-MOFs, Chem. Mater. 2010, 22, 6632-6640.

[63] Katz, M. J.; Brown, Z. J.; Colón, Y. J.; Siu, P. W.; Scheidt, K. A.; Snurr, R. Q.; Hupp, J. T.; Farha, O. K. A facile synthesis of UiO-66, UiO-67 and their derivatives. Chem. Commun. 2013, 49, 9449-9451.

[64] L. Zhang, H. Chen, Z. Zha, Z. Wang, Electrochemical tandem synthesis of oximes from alcohols using $\mathrm{KNO}_{3}$ as the nitrogen source, mediated by tin microspheres in aqueous medium, Chem. Commun. 2012, 28, 6574-6576.

[65] C. S. Hinde, W. R. Webb, B. K. J. Chew, H. R. Tan, W.-H. Zhang, T. S. A. Hor, R. Raja, Utilisation of gold nanoparticles on amine-functionalised UiO-66 $\left(\mathrm{NH}_{2}\right.$-UiO-66) nanocrystals for selective tandem catalytic reactions, Chem. Commun. 2016, 52, 6557-6560.

[66] M. Thommes, K. Kaneko, A. V. Neimark, J. P. Olivier, F. Rodriguez-Reinoso, J. Rouquerol, K. S. W. Sing, Physisorption of gases, with special reference to the evaluation of surface area and pore size distribution (IUPAC technical report). Pure Appl. Chem. 2015, 87, 1051-1069.

[67] Z.-Y. Sui, Y. Cui, J.-H. Zhu, B.-H. Han, Preparation of three-dimensional graphene oxide-polyethylenimine porous materials as dye and gas adsorbents, ACS Appl. Mater. Interfaces 2013, 5, 9172-9179.

[68] D. A. Beattie, A. Arcifa, I. Delcheva, B. A. Le Cerf, S. V. MacWilliams, A. Rossi, M. Krasowska, Adsorption of ionic liquids onto silver studied by XPS, Colloids Surf. A 2018, 544, 7885.

[69] X. Li, Z.-Y. Sui, Y.-N. Sun, P.-W. Xiao, X.-Y. Wang, B.-H. Han, Polyaniline-derived hierarchically porous nitrogen-doped carbons as gas adsorbents for carbon dioxide uptake, Microporous Mesoporous Mater. 2018, 257, 85-91. 
[70] P.-W. Xiao, L. Zhao, Z.-Y. Sui, B.-H. Han, Synthesis of core-shell structured porous nitrogendoped carbon@silica material via a sol-gel method, Langmuir 2017, 33,6038-6045.

[71] R. Gupta, M. Yadav, R. Gaur, G. Arora, R. K. Sharma, A straightforward one-pot synthesis of bioactive $N$-aryl oxazolidin-2-ones via a highly efficient $\mathrm{Fe}_{3} \mathrm{O}_{4} @ \mathrm{SiO}_{2}$-supported acetate-based butylimidazolium ionic liquid nanocatalyst under metal- and solvent-free conditions, Green Chem. 2017, 19, 3801-3812.

[72] A. Elmakssoudi, K. Abdelouahdi, M. Zahouily, J. Clark, A. Solhy, Efficient conversion of aldehydes and ketones into oximes using a nanostructured pyrophosphate catalyst in a solvent-free process, Catal. Commun. 2012, 29, 53-57.

[73] T. S. Ribeiro, A. Prates, S. R. Alves, J. J. Oliveira-Silva, C. A. S. Riehl, J. D. Figueroa-Villar, The effect of neutral oximes on the reactivation of human acetylcholinesterase inhibited with paraoxon, J. Braz. Chem. Soc. 2012, 23, 1216-1225.

[74] C. Van Doorslaer, J. Wahlen, P. Mertens, K. Binnemans, D. De Vos, Immobilization of molecular catalysts in supported ionic liquid phases, Dalton Trans. 2010, 39, 8377-8390.

[75] A. Zhu, T. Jiang, B. Han, J. Zhang, Y. Xie, X. Ma, Supported choline chloride/urea as a heterogeneous catalyst for chemical fixation of carbon dioxide to cyclic carbonates, Green Chem. 2007, 9, 169-172.

[76] A. Corma, H. García, F. X. Llabrés i Xamena, Engineering metal organic frameworks for heterogeneous catalysis, Chem. Rev. 2010, 110, 4606-4655.

[77] J. Chen, K. Shen, Y. Li, Greening the processes of metal-organic framework synthesis and their use in sustainable catalysis, ChemSusChem 2017, 10, 3165-3187.

[78] A. Khoramabadi-Zad, M. Azadmanesh, A. Rezaee, Simple, Efficient and green synthesis of oximes under ultrasound irradiation, S. Afr. J. Chem. 2010, 63, 192-194. 


\section{A synergic activity of urea/butyl imidazolium ionic liquid supported on UiO-66- $\mathrm{NH}_{2}$ metal- organic framework for synthesis of oximes}

Saeed Askari, ${ }^{1}$ Mohammad Jafarzadeh, ${ }^{1 *}$ David Benjamin Christensen, ${ }^{2}$ Søren Kegnæs ${ }^{2}$

${ }^{1}$ Faculty of Chemistry, Razi University, Kermanshah 67149-67346, Iran

${ }^{2}$ Department of Chemistry, Technical University of Denmark, 2800 Kgs. Lyngby, Denmark

*Corresponding author (M. Jafarzadeh): Email: m.jafar@razi.ac.ir

\section{Characterization of 1-(4-bromo-butyl)- $1 \mathrm{H}$-imidazole}

The ionic liquid was prepared and identified by ${ }^{1} \mathrm{H}$ and ${ }^{13} \mathrm{C}$ NMR (Figure S1-S4). In Figure S1, the peak at $1.8 \mathrm{ppm}$ is related to the $\mathrm{CH}_{2}-\mathrm{CH}_{2}$ (number 6 and 7). The peak at $4.2 \mathrm{ppm}$ is assigned to the $\mathrm{CH}_{2}-\mathrm{N}$ (number 4). The peak of $\mathrm{CH}_{2}-\mathrm{Br}$ seems to be covered by a broad peak of HDO. The peaks at 7.7-7.9 ppm are corresponded to the hydrogens of the ring (number 2 and 3), whereas peak at 9.1-9.3 ppm is related to the hydrogen between the two nitrogen atoms (number 1). For ${ }^{13} \mathrm{C}$ NMR (Figure $\mathrm{S} 2$ ), the peaks at 26.4 and $26.6 \mathrm{ppm}$ are related to the carbons numbered 6 and 7 . The peaks at 48.1 and $48.5 \mathrm{ppm}$ are attributed to the $\mathrm{CH}_{2}-\mathrm{Br}$ and the $\mathrm{CH}_{2}-\mathrm{N}$, respectively. The peaks at 122 and 136 ppm are corresponded to the carbons numbered 2 and 3, respectively in the ring. The peak at 119 is assigned to the carbon between the two nitrogen atoms (number 1).

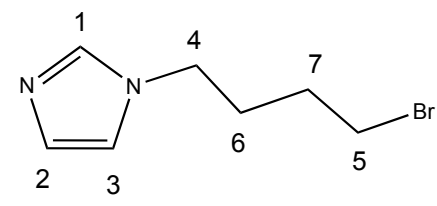




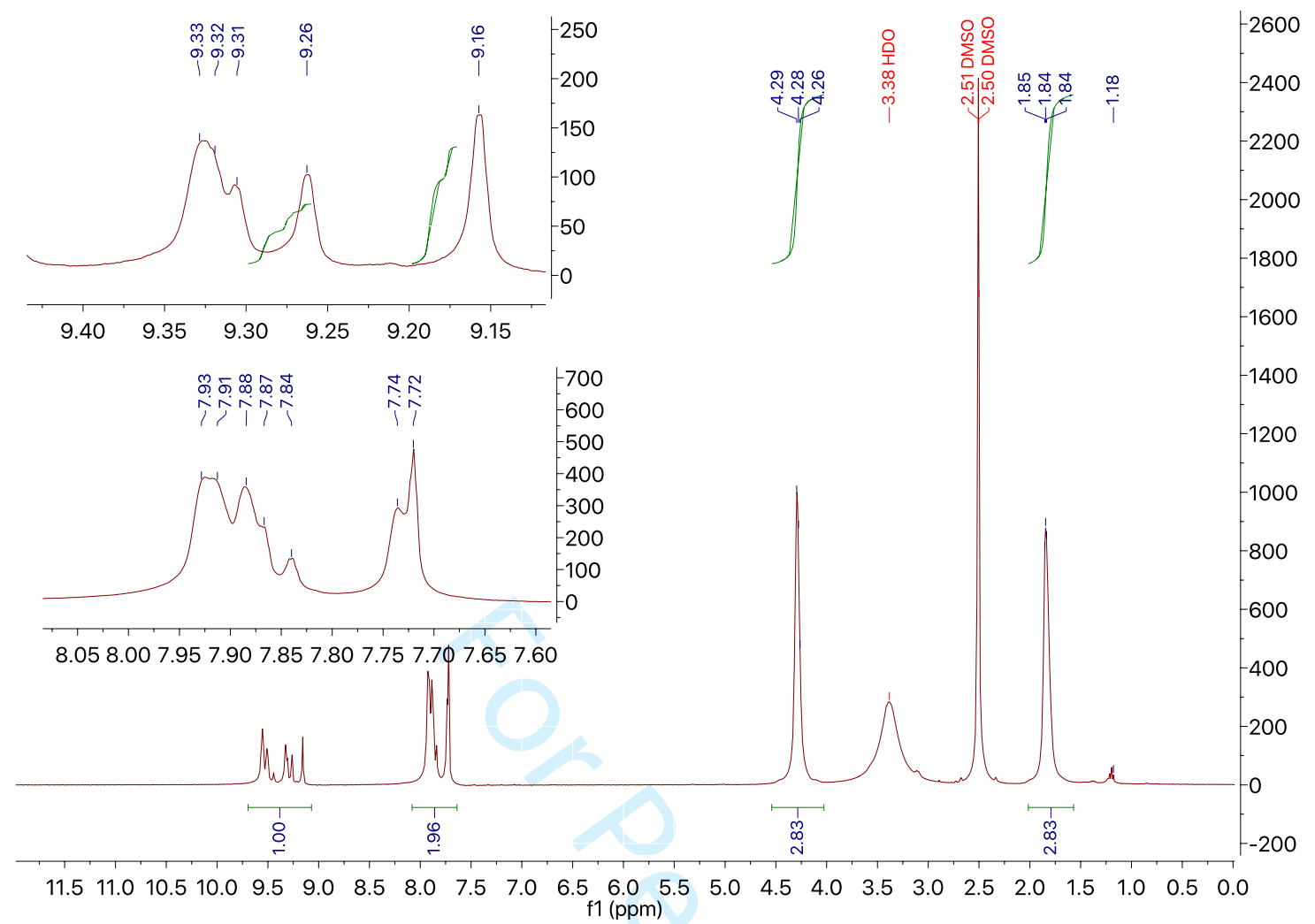

Figure S1. ${ }^{1} \mathrm{H}$ NMR (400 MHz, $d_{6}$-DMSO) of 1-(4-bromo-butyl)-1H-imidazole.

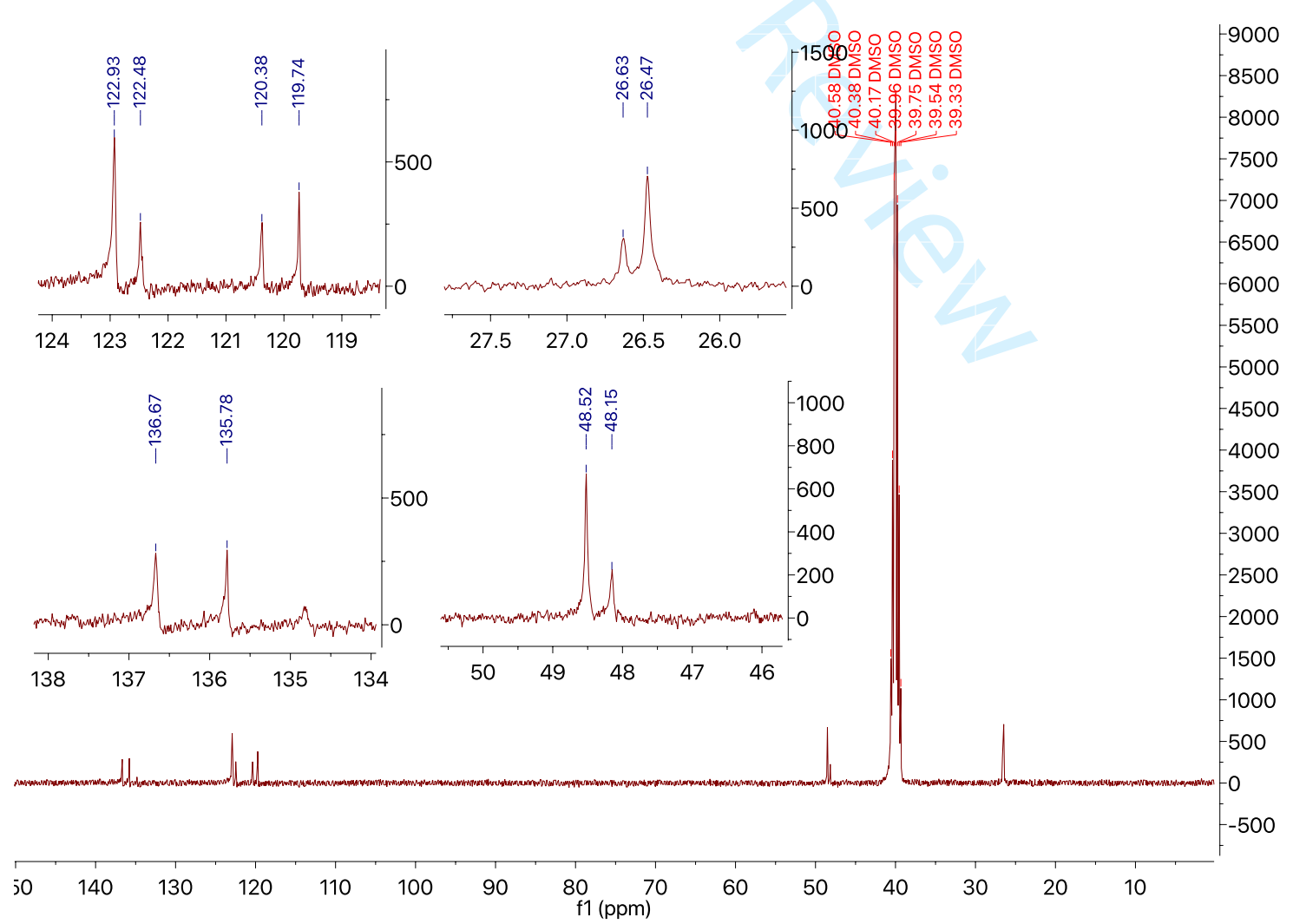

Figure S2. ${ }^{13} \mathrm{C}$ NMR (100 MHz, $d_{6}$-DMSO) of 1-(4-bromo-butyl)-1H-imidazole. 


\section{Characterization of 1,3-bis-(4-bromo-butyl)-3H-imidazol-1-ium bromide (ILBr-)}

The structure has a positive charge, which could be located on each nitrogen atom in the ring with respect to their resonance. The alkyl chains connected to both nitrogen atoms are the same and symmetrical and their hydrogens show a similar chemical environment. In Figure S3, the peak at 1.8 ppm is related to $4 \mathrm{H}$ of the carbons numbered 6 and 7, while the peak at 4.2-4.3 ppm is for the hydrogens numbered $4\left(\mathrm{CH}_{2}-\mathrm{N}\right)$. The corresponding peak of the $\mathrm{CH}_{2}-\mathrm{Br}$ seemed to overlap with the peak of HDO at $3.3 \mathrm{ppm}$. The peaks at 7.7-7.9 are related to the hydrogens numbered 2 and 3 in the ring, whereas the peak at $9.5 \mathrm{ppm}$ is for the hydrogen numbered 1 . In ${ }^{13} \mathrm{C}$ NMR (Figure S4), the peak at $26.5 \mathrm{ppm}$ is related to the carbons numbered 6 and 7. The peak at $48.5 \mathrm{ppm}$ corresponded to $\mathrm{CH}_{2}-\mathrm{Br}$ and $\mathrm{CH}_{2}-\mathrm{N}$. The peaks at 135.8 and $136.7 \mathrm{ppm}$ are assigned to the carbons numbered 2 and 3 , respectively in the ring. The peak at $122.9 \mathrm{ppm}$ is attributed to the carbon numbered 1.

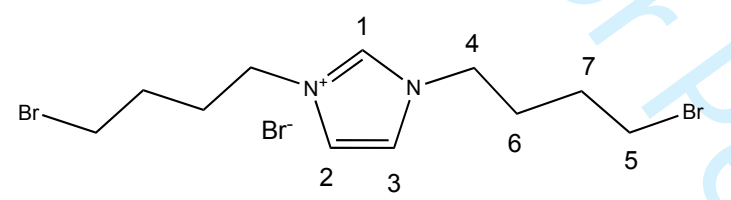




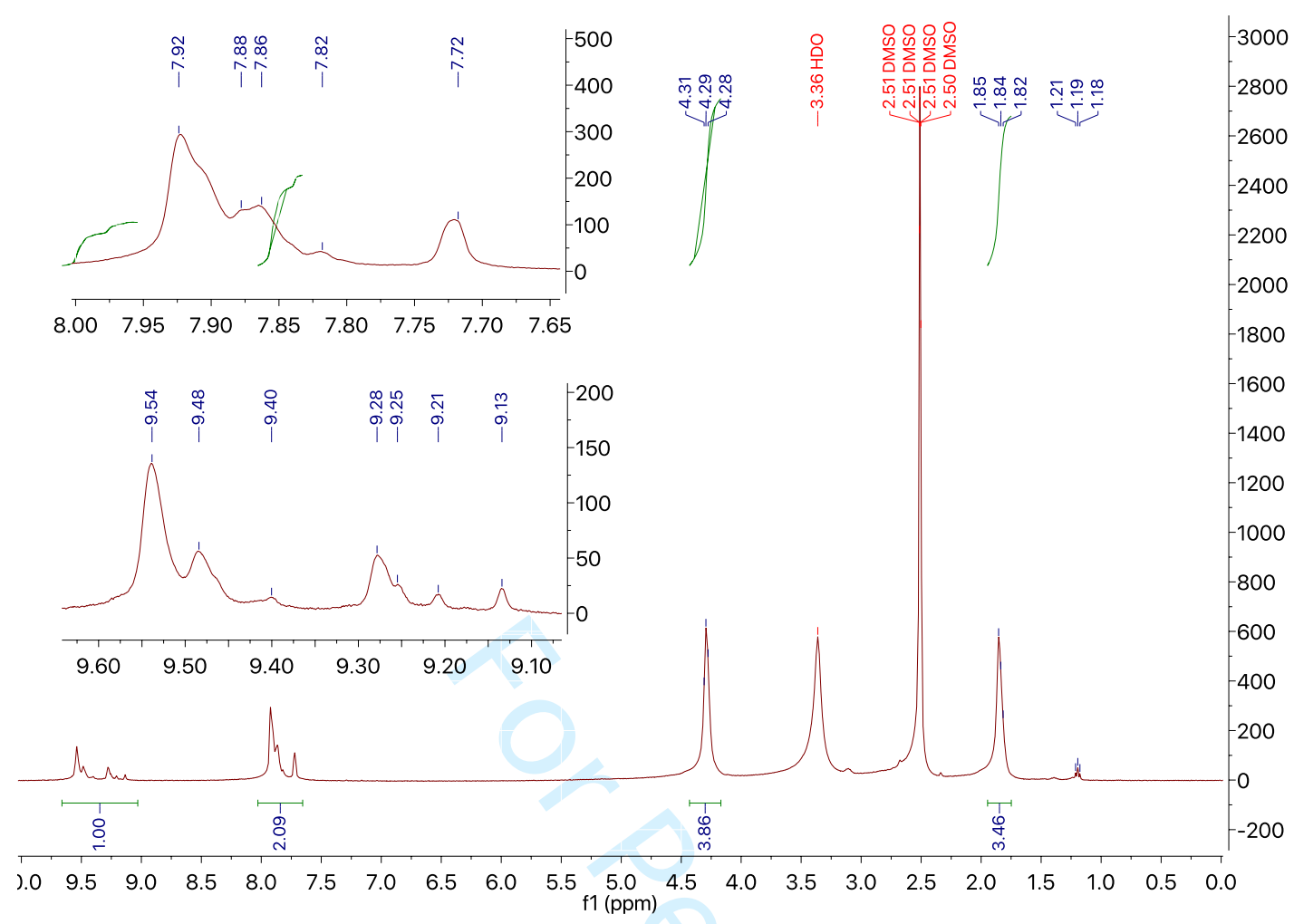

Figure S3. ${ }^{1} \mathrm{H}$ NMR (400 MHz, $d_{6}$-DMSO) of 1,3-bis-(4-bromo-butyl)-3H-imidazol-1-ium bromide.

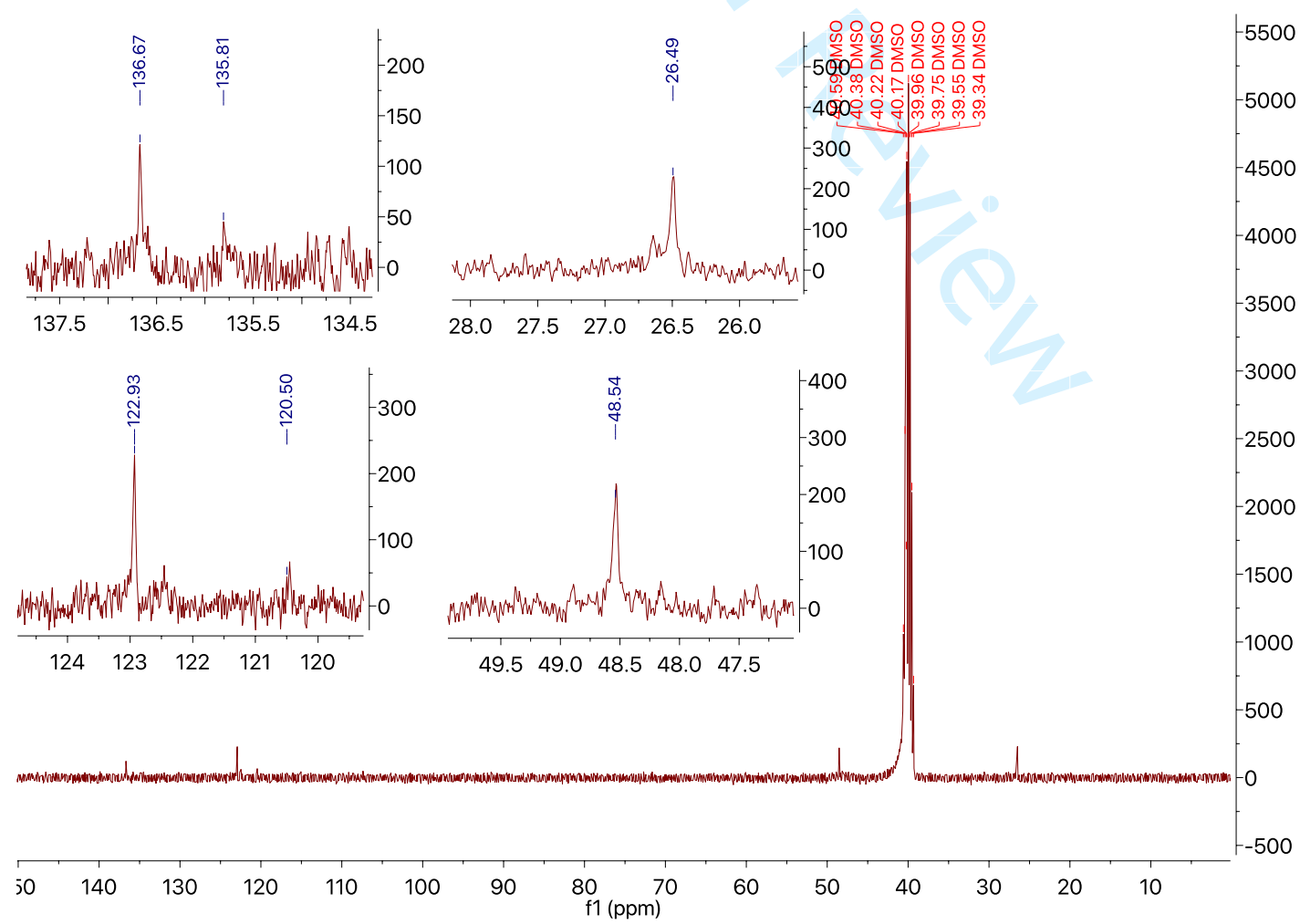

Figure S4. ${ }^{13} \mathrm{C}$ NMR (100 MHz, $d_{6}$-DMSO) of 1,3-bis-(4-bromo-butyl)-3H-imidazol-1-ium bromide. 


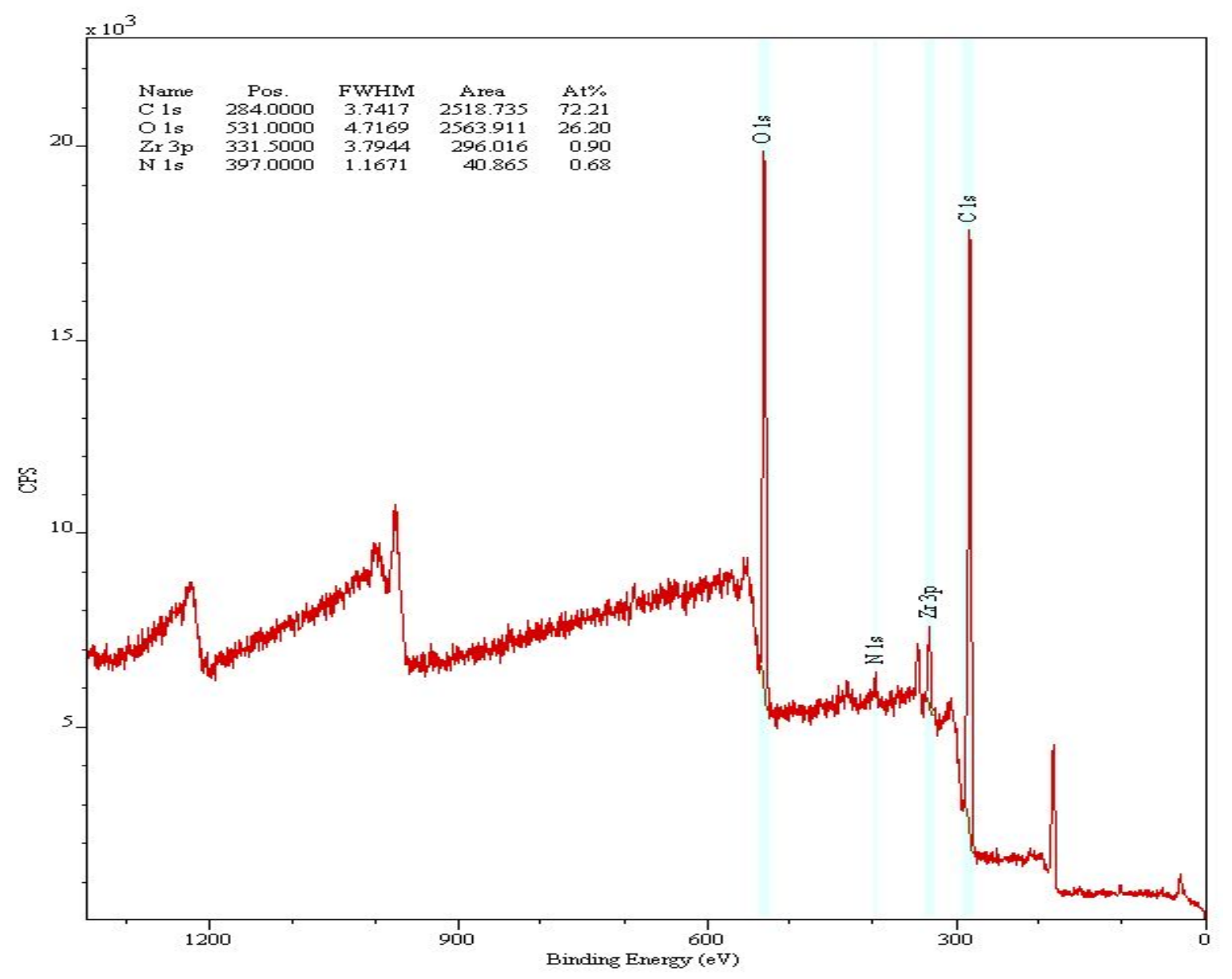

Figure S5. XPS survey of UiO-66- $\mathrm{NH}_{2}$. 


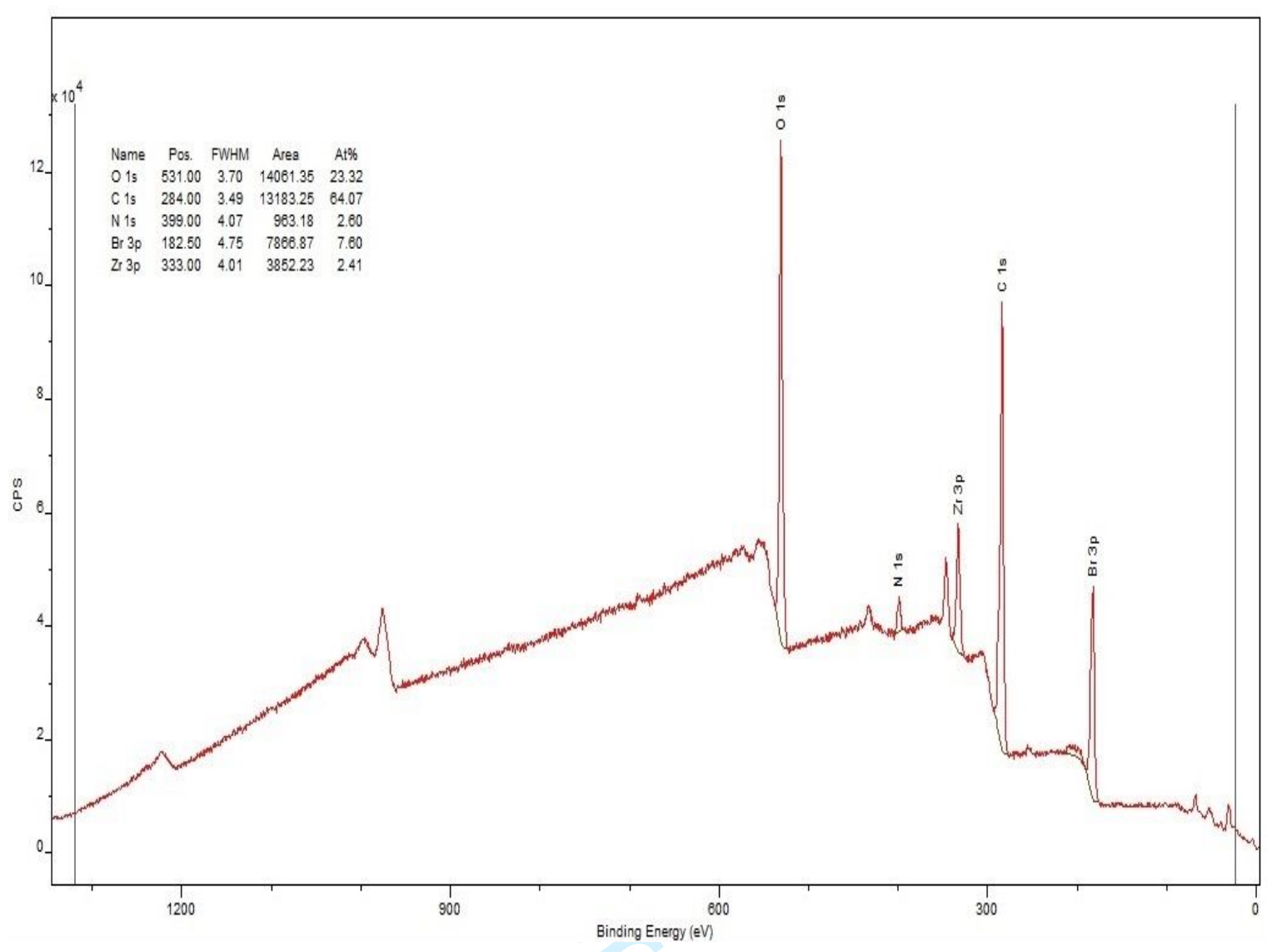

Figure S6. XPS survey of UiO-66- $\mathrm{NH}_{2}-\mathrm{ILBr}^{-}$.

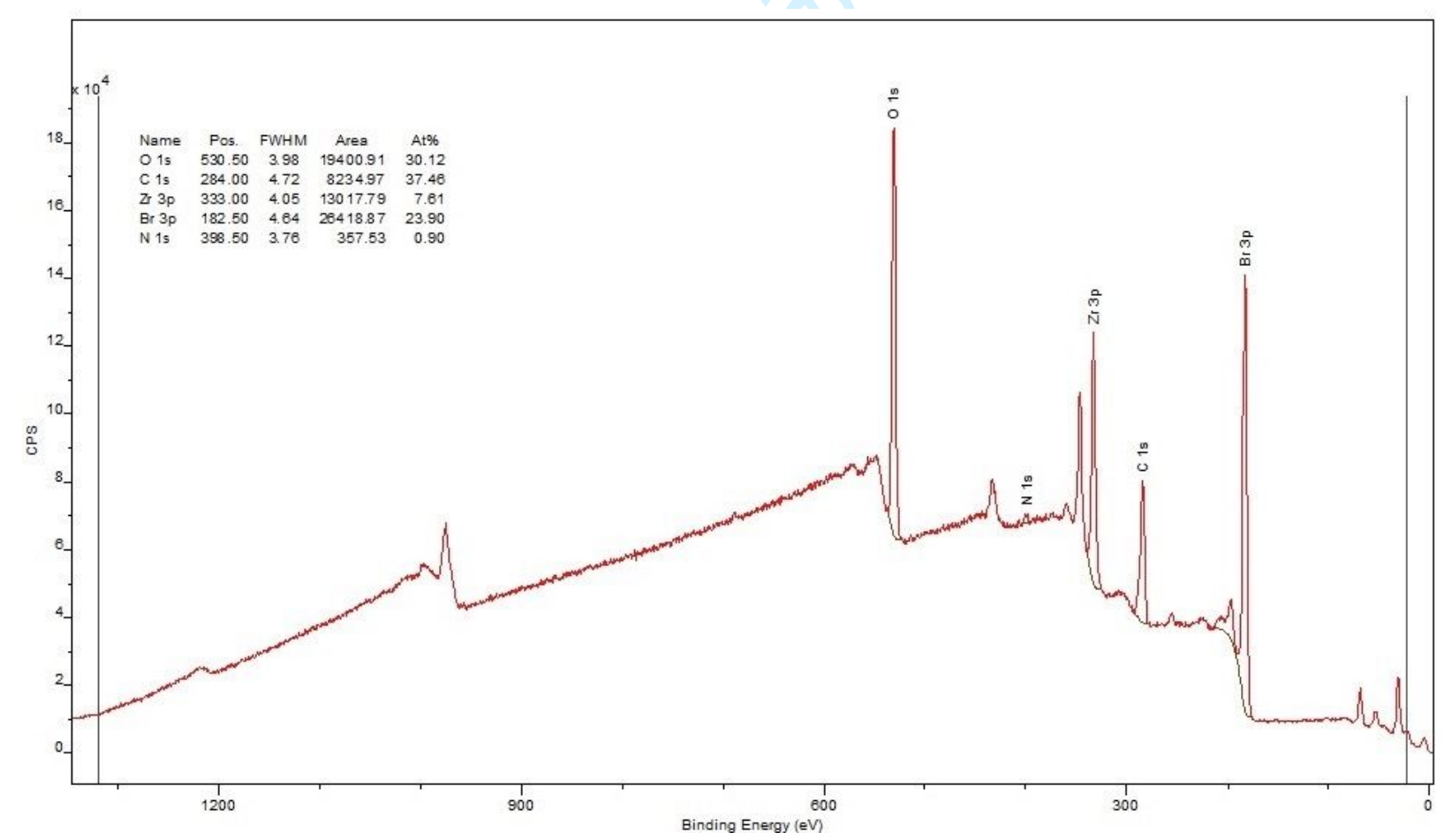

Figure S7. XPS survey of UiO-66- $\mathrm{NH}_{2}-\mathrm{ILBr}^{-}$-urea. 


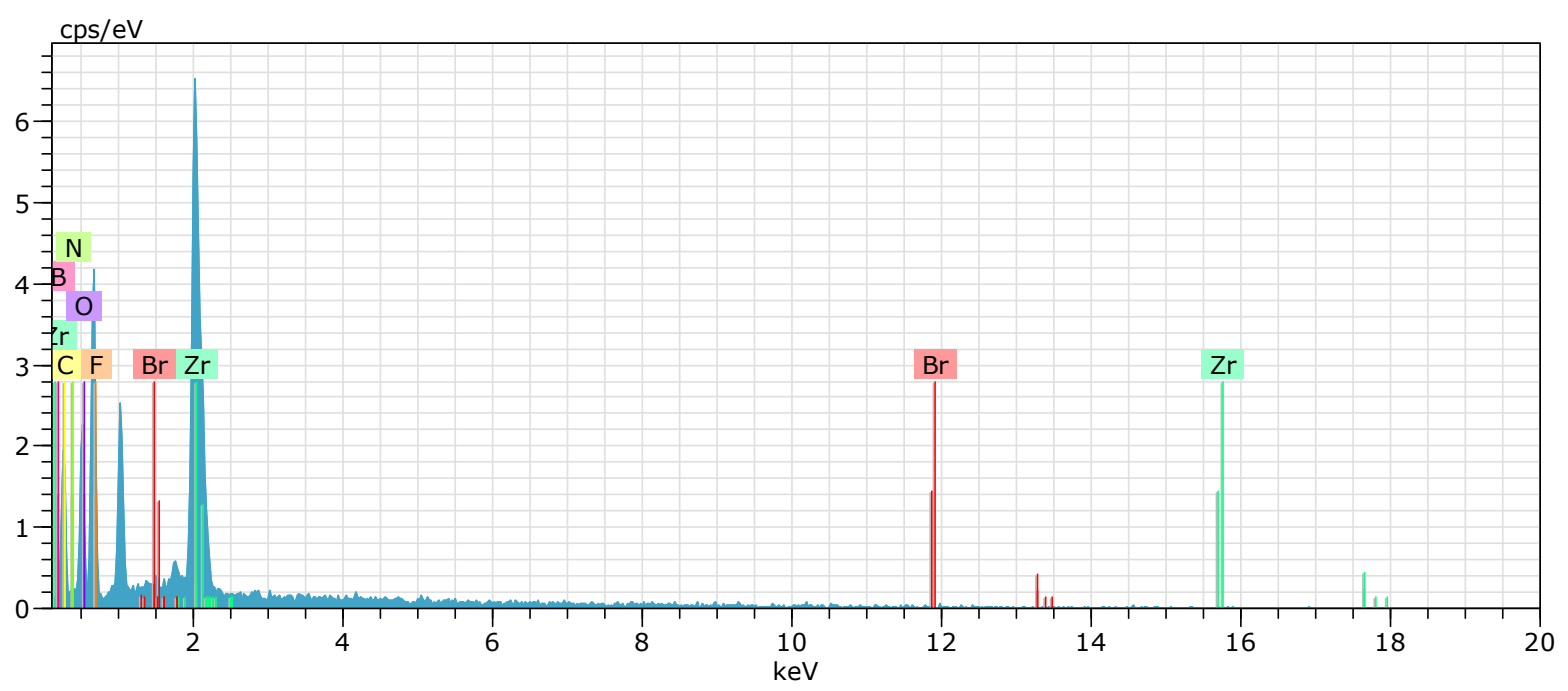

\begin{tabular}{|l|l|l|l|}
\hline Elements & Series & Content (wt.\%) & Content (At.\%) \\
\hline $\mathrm{Zr}$ & L-series & 22.56 & 4.42 \\
\hline $\mathrm{O}$ & K-series & 16.69 & 18.65 \\
\hline $\mathrm{C}$ & K-series & 26.28 & 39.12 \\
\hline $\mathrm{N}$ & K-series & 4.08 & 5.21 \\
\hline $\mathrm{B}$ & K-series & 5.64 & 9.33 \\
\hline $\mathrm{F}$ & K-series & 24.74 & 23.28 \\
\hline $\mathrm{Br}$ & K-series & 0.01 & 0.00 \\
\hline Total & & $\mathbf{1 0 0}$ & $\mathbf{1 0 0}$ \\
\hline
\end{tabular}

Figure S8. EDS spectrum of the catalyst after five-times reuse.
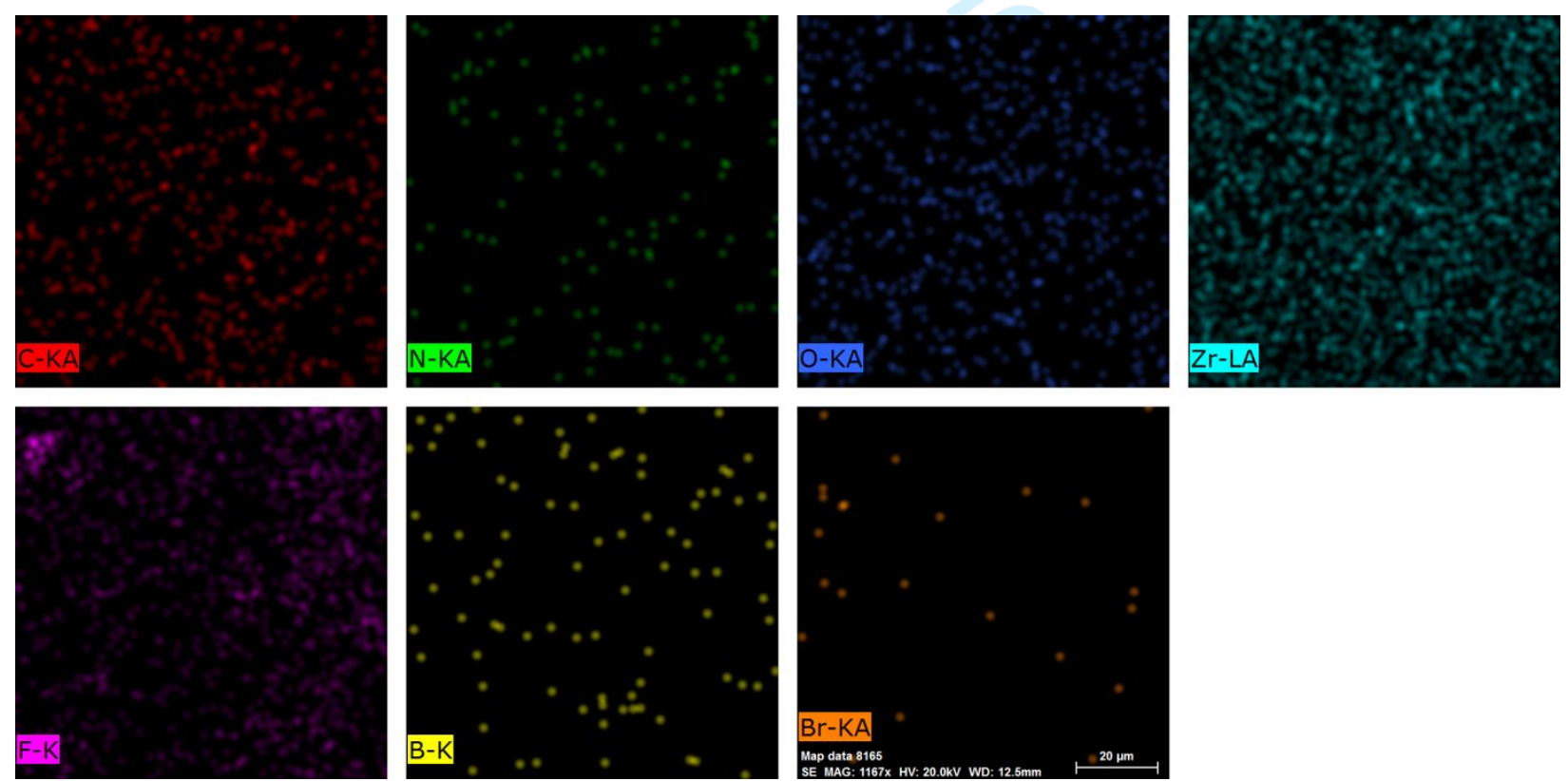

Figure S9. The elemental mapping in selected area of the catalyst after five-times reuse. 


\section{NMR spectra for selected oximes}
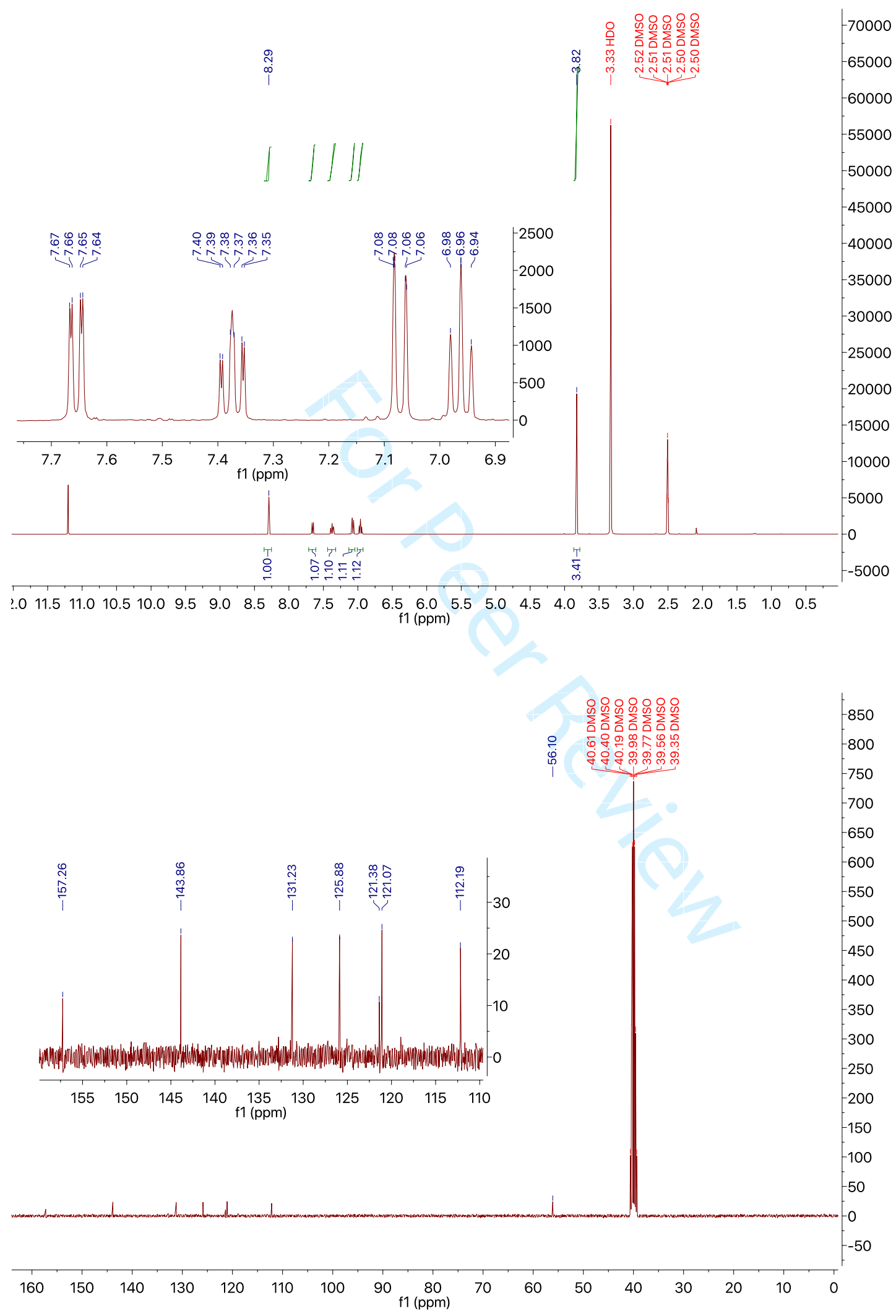

Figure S10. ${ }^{1} \mathrm{H}$ NMR (400 MHz) and ${ }^{13} \mathrm{C}$ NMR (100 MHz) of 2-methylbenzaldehyde oxime (Entry $3)$. 

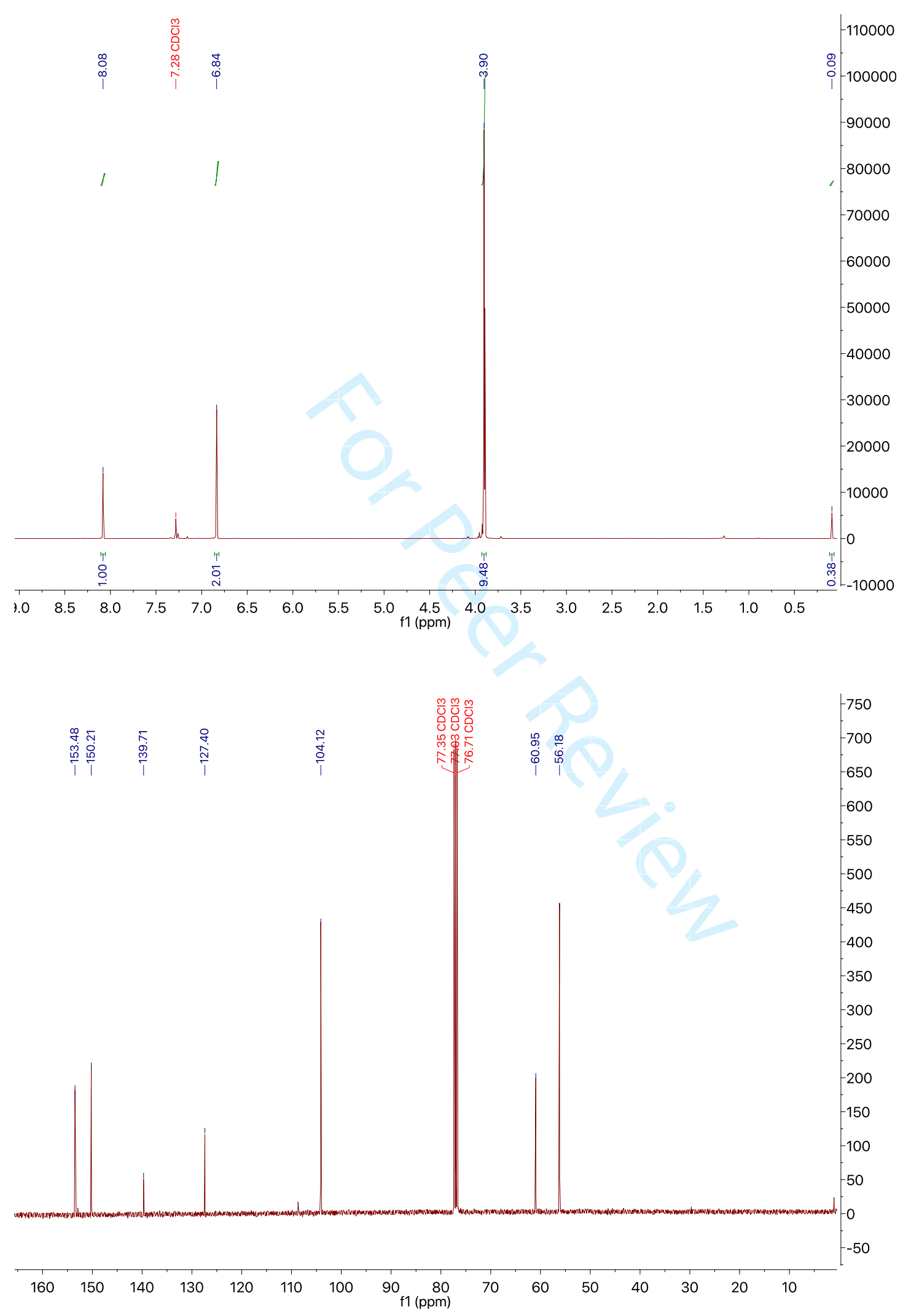

Figure S11. ${ }^{1} \mathrm{H}$ NMR $(400 \mathrm{MHz})$ and ${ }^{13} \mathrm{C}$ NMR $(100 \mathrm{MHz})$ of 3,4,5-trimethoxybenzaldehyde oxime (Entry 4). 


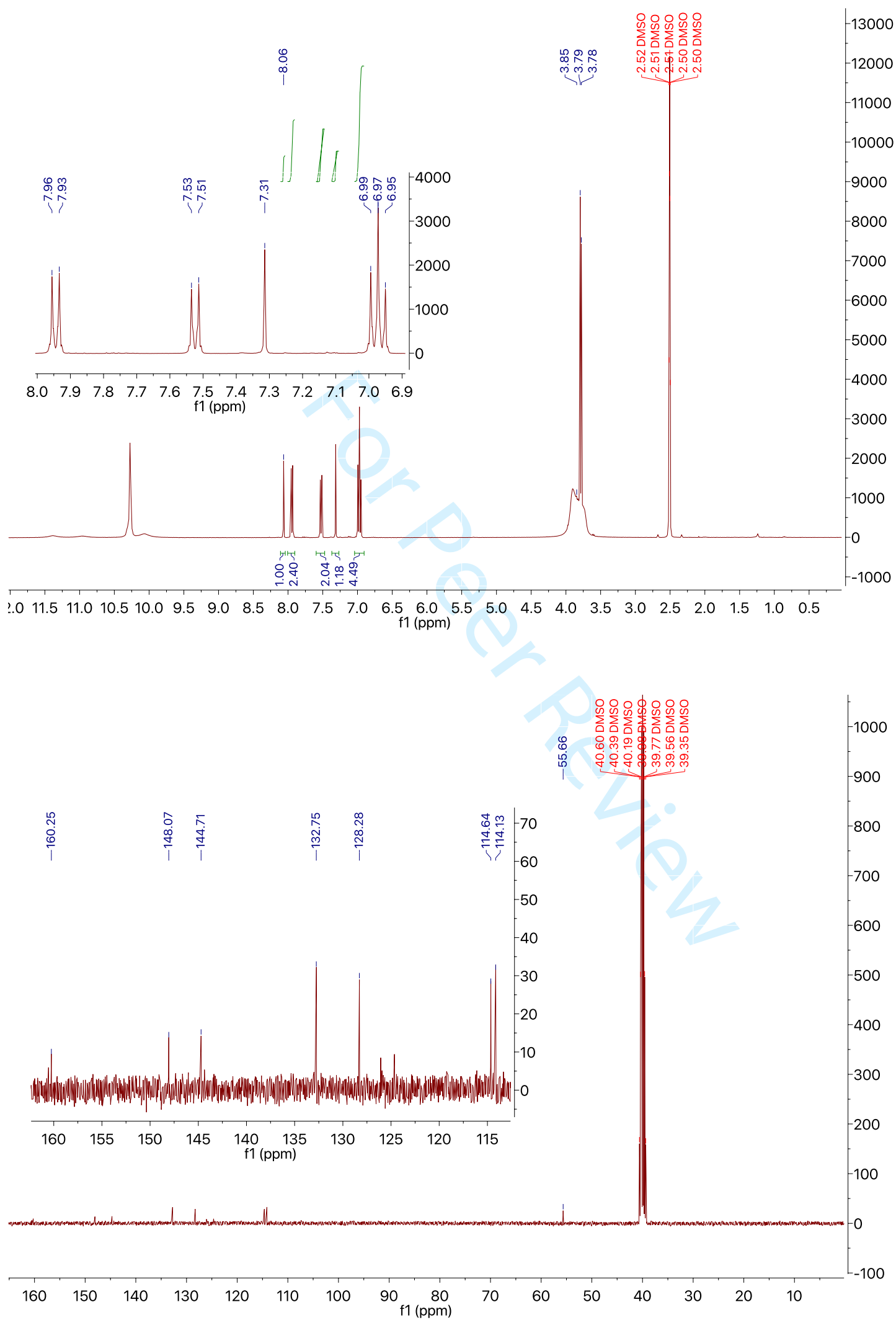

Figure S12. ${ }^{1} \mathrm{H}$ NMR (400 MHz) and ${ }^{13} \mathrm{C}$ NMR (100 MHz) of 4-methoxybenzaldehyde oxime (Entry 9). 